\title{
Desenvolvimento desigual: evidências para o Brasil
}

\author{
Flávia Chein*, Mauro Borges Lemos ${ }^{\dagger}$, Juliano Junqueira Assunção ${ }^{\ddagger}$
}

Sumário: 1. Introdução; 2. Base de Dados; 3. Metodologia de Identificação de Conglomerados Espaciais; 4. Resultados; 5. Conclusão; A. Tabelas e Figuras.

Palavras-chave: desenvolvimento econômico; análise regional; convergência; desigualdade. Códigos JEL: 011; 018; R11.

0 artigo descreve o processo de desenvolvimento da economia brasileira, ocorrido no período de 1970 a 2000, a partir dos dados dos Censos Demográficos, buscando identificar sinais de convergência ou agravamento das desigualdades regionais. Os resultados apontam para a existência de um processo de desenvolvimento desigual que é preservado ao longo das três décadas e vai além das divisões administrativas das Unidades da Federação ou da partição do país entre Norte, Nordeste, Centro-Oeste, Sul e Sudeste.

This paper presents the Brazilian process of economic development over the 1970-2000 period, analyzing whether there is convergence or not across municipalities. Based on data from the Demographic Census, the results point out to an unequal development process among regions. There is no evidence of convergence in the three decades analyzed, and the spatial heterogeneity goes beyond the geographical administrative divisions of the States or the macro regions North, Northeast, Central-West, Southeast and South.

\section{INTRODUÇÃO}

Será que a diferença observada nos indicadores das regiões mais pobres do Nordeste brasileiro em relação às áreas mais desenvolvidas do país tende a se reduzir ao longo do tempo? As condições de vida das áreas mais pobres tendem a convergir para aquelas experimentadas pelas regiões mais ricas do país?

*CEDEPLAR/UFMG. E-mail: fche in@cedeplar .ufmg.br.Rua Curitiba, 832/ $9^{\circ}$.Andar - sala 903. Centro - Belo Horizonte - MG. CEP: $30170-120$

${ }^{\dagger}$ CEDEPLAR/UFMG. E-mail: mbl@cedeplar.ufmg . br.Rua Curitiba, 832/ 9 Andar. Centro - Belo Horizonte - MG. CEP: 30170-120 ${ }^{\ddagger}$ Departamento de Economia PUC-Rio. E-mail: juliano@econ.puc-rio.br. Departamento de Economia. Pontificia Universidade Católica do Rio de Janeiro. Rua Marquês de São Vicente, 225 - Gávea.CEP: 22453-900. Rio de Janeiro, RJ. 
O tópico de convergência entre diferentes economias tem atraído a atenção de economistas desde o modelo neoclássico de crescimento econômico de Solow (1956), cujo resultado principal é uma tendência progressiva de redução nas diferenças nas rendas relativas entre economias ricas e pobres. (Baumol, 1986, Kormendi e Meguire, 1985, Grier e Tullock, 1989, Barro, 1991, Barro e Sala-i Martin, 1992, Mankiw et alii, 1992, Durlauf e Johnson, 1995, Holtz-Eakin, 1993, Sala-i Martin, 1996, Lee et alii, 1997). Os estudos empíricos têm testado desde a hipótese de convergência $\beta$ absoluta, com níveis de renda convergindo para um mesmo nível estacionário, e de convergência condicional, incorporando diferenças em parâmetros estruturais como dotação de capital humano, até a dispersão das rendas entre países e regiões, mediante o teste de $\sigma$ convergência, e a identificação de clubes de convergência, na ausência de convergência em todo o conjunto amostral. No Brasil, são vários os estudos que buscam entender as trajetórias de crescimento das diferentes regiões e Estados da Federação a partir de equações de convergência de renda per capita (Ferreira e Diniz, 1995, Ferreira e Ellery Jr., 1996, Azzoni, 2001, Azzoni et alii, 2000, Laurini et alii, 2005).

Por outro lado, como constatam Ray $(1998,2000)$ e Banerjee e Duflo (2004), tem havido um esforço para a recuperação de idéias embutidas em estudos pioneiros da teoria de desenvolvimento, entre os quais se incluem os de Rosenstein-Rodan (1943), Nurske (1953), Fleming (1955), Hirschman (1958) e Myrdal (1957), que apontam na direção oposta à de convergência. Isto é, levantam a possibilidade do desenvolvimento econômico resultar de mecanismos que possibilitam grandes desigualdades, seja entre países seja entre regiões. Tipicamente, os argumentos decorrem de falhas de coordenação ou falhas de mercado. Tais teorias de desenvolvimento desigual há muito foram incorporadas, direta ou indiretamente, aos estudos brasileiros de economia regional e urbana para explicar o atraso histórico das macrorregiões Norte e Nordeste e o papel de investimentos e incentivos estatais na desconcentração espacial das atividades econômicas (Cano, 1994, Guimarães Neto, 1995, Haddad, 1993, 1996, Diniz e Lemos, 1989, Magalhães, 1983, Oliveira, 1990, Araújo, 1995, Galvão, 1996).

Este artigo descreve o processo de desenvolvimento da economia brasileira nos últimos 30 anos, sob uma perspectiva regional, com o intuito de investigar se há indícios de convergência ou se existem regiões que se mantiveram excluídas ou relativamente menos beneficiadas dos avanços do período.

Nesses trinta anos compreendidos entre 1970 e 2000, houve uma melhora significativa do país em uma série de indicadores correlacionados ao nível de desenvolvimento. A média de anos de estudo da população com 25 anos ou mais vem aumentando cerca de um ano a cada dez anos - em 1970 era de 3,4 anos de estudo, enquanto que, em 2000, alcançou o patamar 5,9 anos de estudo. Por outro lado, analisando os indicadores de infra-estrutura, verifica-se um aumento da população atendida por rede geral de abastecimento e esgoto. $O$ percentual de pessoas residentes em domicílios atendidos por rede geral de abastecimento saltou de $30,39 \%$, em 1970 , para $75,82 \%$, em 2000 . 0 acesso a esgotamento sanitário, por sua vez, aumentou de $11,68 \%$ para $44,76 \%$ no mesmo período. Mas será que a melhora significativa em tais indicadores ocorreu de forma homogênea nos diversos municípios? Diante desse quadro, podemos afirmar que as economias regionais estão convergindo para um mesmo estado estacionário?

Para responder essas perguntas, conforme sugerido por Sen (1984), diferentes dimensões do desenvolvimento econômico são explicitamente consideradas na nossa análise: a garantia a serviços de infra-estrutura, como saneamento, esgotamento sanitário e iluminação; o acesso à educação (representada por indicadores como média de anos de estudo, taxas de alfabetização/analfabetismo e percentual de crianças na escola), ao trabalho (verificado pelas condições de emprego e qualidade dos postos de trabalho), e a bens de consumo duráveis. ${ }^{1}$

Os resultados são derivados em três etapas.

Primeiro, a partir da análise de componentes principais das variáveis sócio-econômicas do Censo Demográfico de 1970, são construídos atributos municipais sobre população, estrutura produtiva, mercado de trabalho, estrutura familiar, infra-estrutura domiciliar, rendimentos, desigualdade e educação,

\footnotetext{
${ }^{1}$ Alguns autores, como Lucas (1988), argumentam que essas dimensões podem ser capturadas pela renda per capita, dada a elevada correlação entre essa variável e os indicadores já citados.
} 
a partir de 58 variáveis resumidas em 19 componentes principais. Estes diferentes aspectos das condições sócio-econômicas municipais visam a uma caracterização dos parâmetros estruturais e dotações da economia no momento inicial da análise.

A segunda etapa é de regionalização dos municípios pela construção de conglomerados espaciais homogêneos. Utilizando os vetores de atributos municipais, obtidos pela análise de componentes principais, identificamos 400 regiões através de uma variante espacial do algoritmo de redução à árvore geradora desenvolvido por Maravalle e Simeone (1995). O objetivo desta etapa de análise é a obtenção de regiões contíguas que apresentam similaridades em termos das condições sócio-econômicas consideradas, estabelecendo áreas para as quais parâmetros estruturais e dotações sejam semelhantes.

Finalmente, a terceira etapa identifica as vinte regiões mais desenvolvidas e as vinte regiões menos desenvolvidas com base em atributos municipais. A hierarquia dessas regiões foi feita com base nos valores médios dos municípios de cada região em seis componentes principais: rendimento por trabalhador, emprego e trabalho infantil; emprego formal; tamanho da família; infra-estrutura domiciliar, renda e educação. Fizemos um ordenamento das regiões, das mais para as menos desenvolvidas em cada um dos componentes e, em seguida, a partir do somatório dos postos associados ao ordenamento, definimos as vinte regiões de maior e menor desenvolvimento.

Todas as vinte regiões de menor desenvolvimento estão localizadas na Região Nordeste e no Estado de Minas Gerais. De outro lado, entre as vinte regiões enquadradas como mais desenvolvidas, oito são capitais, incluindo uma na região Nordeste e outra no Norte (São Paulo, Belo Horizonte, Rio de Janeiro, Goiânia, Florianópolis, Curitiba, Salvador, Belém).

A comparação das trajetórias dos indicadores sócio-econômicos entre esses dois grupos de regiões permite averiguar a ocorrência ou não de convergência ao longo dos 30 anos analisados. As diferenças observadas entre as regiões mais desenvolvidas e menos desenvolvidas são enormes.

Os resultados mostram que o processo de melhoria nos indicadores econômicos entre 1970 e 2000 ocorreu de forma a manter grande parte do diferencial já existente em 1970. As exceções se referem aos indicadores de posição ocupacional e acesso a serviços públicos de iluminação elétrica. Os indicadores de renda, educação e acesso a demais serviços públicos preservam a diferença observada em 1970 , quando não a ampliam.

Em 1970, o rendimento per capita nas vinte regiões mais desenvolvidas era de $\mathrm{R} \$ 117,47$ contra $\mathrm{R} \$ 22,28$ nas regiões de menor desenvolvimento. Trinta anos depois, o valor do rendimento per capita nas vinte regiões menos desenvolvidas é de apenas $\mathrm{R} \$ 84,03$, enquanto nas regiões mais desenvolvidas alcança a cifra de $\mathrm{R} \$ 387,09$. A média de anos de estudo da população com 25 anos ou mais, nas vinte regiões mais desenvolvidas, passou de 3,14 para 6,64 , ao passo que nas vinte regiões menos desenvolvidas se elevou de 0,6 para apenas 2,9 anos de estudos. Já o percentual de residentes em domicílios com rede geral de esgotamento sanitário nas regiões mais desenvolvidas aumentou de $31 \%$ para $64 \%$, enquanto que, nas regiões de menor desenvolvimento, o percentual que, em 1970, era de menos de $1 \%$, chegou a apenas $15 \%$ em 2000.

Esses resultados contribuem para a literatura de economia regional no Brasil.

Primeiro, por considerar um nível de desagregação muito mais detalhado, o que nos permitiu identificar padrões que não haviam sido documentados e que vão contra parte da evidência empírica disponível. Ferreira e Diniz (1995) encontram convergência absoluta para os estados brasileiros, considerando os valores de PIB per capita estaduais para anos de 1970 a 1985. Para Azzoni (2001), esse teria sido um período de forte redução de desigualdades que não se manteve nos períodos subseqüentes, a análise dos dados de dispersão da renda per capita entre os estados, referentes ao período de 1939-1995, indicam sinais de convergência regional de renda, mas com oscilações significativas na redução da desigualdade no tempo e entre as regiões. Ferreira e Ellery Jr. (1996), por sua vez, utilizando, além dos dados de PIB per capita estaduais para os anos de 1970 a 1985, estimativas para os anos de 1985 a 1990, confirmam a hipótese de convergência $\beta$ e $\sigma$ para o Brasil, mas constatam que a mesma se dá em uma velocidade inferior à encontrada por Barro e Sala-i Martin (1992) para os estados americanos. Azzoni et alii (2000), utilizando dados da PNAD (Pesquisa Nacional por Amostra de Domicílios) para 19 Estados, no período de 
1981 a 1996, concluem que houve um convergência $\beta$ condicional, com cada Estado convergindo para a sua própria situação estacionária em virtude de diferenças estruturais em educação, infra-estrutura e em variáveis geográficas. Já o estudo de Mossi et alii (2003), baseado em medidas de associação espacial, constata que a dinâmica de distribuição de renda é fortemente influenciada por fatores regionais, com dois clusters de convergência de renda: um cluster de baixa renda formado pelos Estados do Piauí, Ceará, Rio Grande do Norte e Bahia e outro de alta renda, englobando os Estados do Rio de Janeiro, São Paulo, Paraná e Minas Gerais.

Segundo, ao organizar os municípios por conglomerados espaciais homogêneos, conseguimos captar diferenças importantes no interior das macrorregiões brasileiras. O estudo de Laurini et alii (2005), que também utiliza dados municipais, constata a existência de dois clubes de convergência - um clube de baixa renda, constituído pelos municípios do Norte e Nordeste e outro de alta renda, formado pelos municípios das regiões Centro-Oeste, Sudeste e Sul, rejeitando a hipótese de convergência para um mesmo nível de renda per capita. Entretanto, ao enquadrar os municípios do Norte e Nordeste em um único grupo de renda baixa, tanto deixa encoberta a dinâmica diferenciada das capitais, como também desconsidera a existência de regiões de baixa renda no Centro-Oeste, Sudeste e Sul, muitas delas que, como o Vale do Jequitinhonha, em Minas Gerais, permanecem à margem do progresso econômico.

Terceiro, ao invés de utilizar os testes tradicionais de convergência de renda per capita, optamos por considerar um conjunto maior de indicadores. Dessa forma, mostramos que a ausência de convergência também se estende para outros indicadores importantes de desenvolvimento, como educação e acesso à infra-estrutura. Logo, ao invés de condicionarmos o crescimento da renda per capita nessas variáveis, como faz o estudo de Azzoni et alii (2000), analisamos a suas próprias trajetórias de crescimento.

As demais seções desse artigo estão organizadas da seguinte forma: a seção 2 descreve a base de dados utilizada; a seção 3 apresenta a metodologia utilizada para definição dos conglomerados espaciais; a seção 4 discute os resultados encontrados, apontando as regiões de menor desenvolvimento e, finalmente, na seção 5 , são tecidos os comentários finais.

\section{BASE DE DADOS}

A base de dados utilizada foi construída a partir dos microdados, ou seja, das informações para pessoas e domicílios, dos Censos Demográficos do Brasil, realizados pelo Instituto Brasileiro de Geografia e Estatística (IBGE), para os anos de 1970, 1980,1991 e 2000. A base de dados abrange todo o território nacional, apresentando representatividade estatística das informações para o nível municipal.

Contudo, a agregação das informações dos quatro últimos censos demográficos em uma base de dados única, com abrangência municipal, requer a compatibilização tanto das malhas municipais quanto das variáveis existentes em cada um desses censos demográficos. Primeiramente, para explorar os dados no âmbito municipal é preciso definir novas unidades territoriais de análise, visto que em 1970 existiam 3981 municípios tendo ocorrido um salto para 5507 municípios em 2000.

Propõe-se, nesse sentido, adotar, como unidade espacial de análise, unidades territoriais que retratem a malha municipal existente em 1970. Para tanto é preciso identificar a origem dos municípios que foram desmembrados ao longo do período de 1970 a 2000, de modo a tornar possível trabalhar com uma mesma malha territorial compatibilizada para todos os quatro anos censitários considerados. ${ }^{2}$

Dos 5507 municípios existentes em 2000, 3951 existiam em 1970, 1185 originaram-se de municípios existentes em 1970, 78 de municípios não existentes em $1970^{3}$ e 293 foram originários de mais de uma localidade. Destes 293 municípios, 80 são compostos por desmembramentos de duas ou mais

\footnotetext{
${ }^{2} \mathrm{~A}$ identificação da origem dos municípios foi viabilizada, inicialmente, por dados fornecidos pela Fundação João Pinheiro, os quais foram complementados por informações disponíveis no site e publicações do IBGE.

${ }^{3}$ Nesse caso, busca-se o município "'mãe"' do município de origem até se chegar a um município já existente em 1970 . Por exemplo, os municípios que foram fundados a partir do desmembramento de Ariquemes (RO), criado em 1977, são agregados a Porto Velho (RO), que é o município de origem de Ariquemes (RO) e tem ano de fundação anterior a 1970.
} 
localidades, mas apenas um dos municípios de origem já existia em 1970, nesse caso, foi feita a opção por re-agregar a parte desmembrada ao município mais antigo, com ano de fundação anterior a 1970.

Para o caso das 113 localidades desmembradas de mais de um município cuja data de fundação é anterior a 1970, o município criado é agregado àquele com maior poder de polarização, fundamentandose na idéia do modelo gravitacional de Isard e Bramhall (1960). De acordo com os autores, a interação entre duas populações é relacionada diretamente ao seu tamanho e inversamente à distância, uma vez que essa envolve fricção, inconveniência e custo.

Desse modo, como poder de polarização, considera-se a relação direta entre o tamanho da população, em 2000, do município de origem (como proxy para o tamanho do mercado) e o inverso da distância ao quadrado entre o centróide do município criado após 1970 e o centróide do município de origem. A idéia é que a contribuição de um dado tamanho de mercado declina à medida que as distâncias relevantes aumentam, ou seja, os efeitos de polarização de um grande mercado são reduzidos à medida que a distância tende a crescer, uma vez que o poder de interação tende a reduzir em virtude, especialmente, do aumento do custo de transporte.

Assim, torna-se possível agregar os 5507 municípios existentes em 2000 em $3950^{4}$ unidades territoriais de análise, com base nos municípios já existentes em 1970. Ressalte-se que, nos Estados do Rio Grande do Sul, de Goiás/Tocantins e de Minas Gerais, houve um maior número de municípios criados, entretanto, a maior decomposição de um município em vários ocorreu no Norte do país, apenas Porto Velho (incluindo os de origem em comum com Guajará-Mirim) deu origem a 43 novos municípios de 1970 para 2000.

Foi necessária também a compatibilização das variáveis censitárias disponíveis. Adotou-se como referência as variáveis e classificações existentes no Censo Demográfico de 1970, ou seja, algumas variáveis foram consideradas com o nível de detalhamento menor do que o existente nos Censos Demográficos de 1991 e 2000. A variável de rendimento, por exemplo, engloba não apenas o rendimento do trabalho, mas o de todas as fontes, uma vez que a informação disponível para o ano de 1970 refere-se apenas ao rendimento médio, não fazendo distinção entre rendimento do trabalho, rendimento do trabalho principal, rendimento de aluguel, rendimento de aposentadoria, pensão, doação, renda mínima, entre outros, como ocorre no Censo 2000.

Uma vez estabelecida uma base de dados longitudinal compatibilizada por unidade territorial de análise, como aproximação para seus parâmetros estruturais e dotações, foram definidos nove grupos de variáveis, apresentados na Tabela 1, conforme a disponibilidade de informações sócio-econômicas: 1) características da população; 2) estrutura produtiva; 3) características do mercado de trabalho; 4) estrutura ocupacional; 5) estrutura familiar; 6) infra-estrutura domiciliar; 7) educação 8) rendimento; 9) desigualdade.

Tabela 1: Descrição das Variáveis e Valores Médios

\begin{tabular}{|l|l|cccc|}
\hline \hline Grupos & Variáveis & 1970 & 1980 & 1991 & 2000 \\
\hline $\begin{array}{l}\text { Unidade Ge- } \\
\text { ográfica de }\end{array}$ Análise & $\begin{array}{l}\text { ferência compatibilizadas para os } \\
\text { Censos de 1970, 1980, 1991 e 2000 }\end{array}$ & & & & \\
\hline & $\begin{array}{l}\text { 1. População total } \\
\text { 2. Percentual da População de 7 a }\end{array}$ & 23,69 & 21,16 & 19,85 & 17,14 \\
& 14 anos & & & & \\
$1-$ Carac. da & & & & & \\
\hline
\end{tabular}

4 Eoppulaça 1970 havia 3952 (excluindo os casos dos municípios do Estado da Guanabara e cidades-satélite de Brasília) municípios, mas o município de Cococi, no Ceará, não consta da malha municipal de 2000, tendo sido incorporado por Parambu (CE). Além disso, para corrigir a quebra de contigüidade geográfica, decorrente do uso do critério de polarização para escolha da origem, o município de Chapada dos Guimarães e seus desmembramentos foram agregados a Nobres. 
Tabela 1 - Continuação

\begin{tabular}{|c|c|c|c|c|c|}
\hline Grupos & Variáveis & 1970 & 1980 & 1991 & 2000 \\
\hline & $\begin{array}{l}\text { 3. Percentual da População de } 15 \\
\text { anos ou mais }\end{array}$ & 55,06 & 58,73 & 63,27 & 68,88 \\
\hline & $\begin{array}{l}\text { 4. Percentual da População de } 25 \\
\text { anos ou mais }\end{array}$ & 35,37 & 38,42 & 43,98 & 49,27 \\
\hline & $\begin{array}{l}\text { 5. Percentual de idosos na popula- } \\
\text { ção (população acima de } 60 \text { anos) }\end{array}$ & 5 & 6,5 & 7,99 & 9,75 \\
\hline & 6. Percentual de Homens & 50,57 & 50,69 & 50,57 & 50,48 \\
\hline & 7. Percentual da População urbana & 32,61 & 43,34 & 54,45 & 62,55 \\
\hline \multirow{7}{*}{$\begin{array}{l}\text { 2-Estrutura } \\
\text { Produtiva }\end{array}$} & $\begin{array}{l}\text { 8. Percentual de Ocupados na Agro- } \\
\text { pecuária }\end{array}$ & 69.71 & 55,75 & 47,87 & 38,07 \\
\hline & $\begin{array}{l}\text { 9. Percentual de Ocupados na Extra- } \\
\text { ção }\end{array}$ & 2,7 & 2,41 & 1,97 & 1,18 \\
\hline & $\begin{array}{l}\text { 10. Percentual de Ocupados na In- } \\
\text { dústria Moderna }\end{array}$ & 0,93 & 1,69 & 2,39 & 1,68 \\
\hline & $\begin{array}{l}\text { 11. Percentual de Ocupados na In- } \\
\text { dústria Tradicional }\end{array}$ & 4,08 & 6,51 & 6,37 & 6,78 \\
\hline & $\begin{array}{l}\text { 12. Percentual de Ocupados na } \\
\text { Construção Civil }\end{array}$ & 3,44 & 5,25 & 5,2 & 5,63 \\
\hline & $\begin{array}{l}\text { 13. Percentual de Ocupados em Ser- } \\
\text { viços }\end{array}$ & 14,07 & 19,07 & 26,83 & 29,29 \\
\hline & $\begin{array}{l}\text { 14. Percentual de Ocupados no Co- } \\
\text { mércio }\end{array}$ & 4,46 & 6,18 & 8,98 & 11,77 \\
\hline
\end{tabular}


Tabela 1 - Continuação

\begin{tabular}{|c|c|c|c|c|c|}
\hline Grupos & Variáveis & 1970 & 1980 & 1991 & 2000 \\
\hline \multirow{8}{*}{$\begin{array}{l}\text { 3-Carac. do } \\
\text { Mercado de } \\
\text { Trab. }\end{array}$} & 15. Taxa de Ocupação & 44,26 & 97,98 & 95,94 & 88,45 \\
\hline & 16. Taxa de Atividade & 44,7 & 47,34 & 50,03 & 54,26 \\
\hline & 17. Rendimento por Trabalhador & 146,91 & 338,94 & 290,66 & 446,06 \\
\hline & $\begin{array}{l}\text { 18. Percentual de ocupados como } \\
\text { Empregados }\end{array}$ & 49,5 & 53,42 & 57,77 & 58,81 \\
\hline & $\begin{array}{l}\text { 19. Percentual de ocupados como } \\
\text { Empregadores }\end{array}$ & 1,39 & 2,29 & 3,21 & 1,98 \\
\hline & $\begin{array}{l}\text { 20. Percentual de ocupados como } \\
\text { Conta-própria }\end{array}$ & 35,96 & 34,3 & 32,01 & 24,87 \\
\hline & $\begin{array}{l}\text { 21. Percentual de ocupados sem re- } \\
\text { muneração }\end{array}$ & 13,68 & 9,15 & 7,02 & 14,34 \\
\hline & $\begin{array}{l}\text { 22. Percentual de crianças (de } 10 \text { a } \\
14 \text { anos) que trabalham ou procu- } \\
\text { ram trabalho }\end{array}$ & 12,63 & 13,32 & 10,72 & 9,78 \\
\hline \multirow{9}{*}{$\begin{array}{l}\text { 4-Estrutura } \\
\text { Ocupacional }\end{array}$} & $\begin{array}{l}\text { 23. Percentual em Ocupações Admi- } \\
\text { nistrativas }\end{array}$ & 5,27 & 6,06 & 7,91 & 6,73 \\
\hline & $\begin{array}{l}\text { 24. Percentual em Ocupações Técni- } \\
\text { cas, Científicas, Artísticas e Asseme- } \\
\text { lhadas }\end{array}$ & 2,9 & 3,99 & 5,64 & 6,76 \\
\hline & $\begin{array}{l}\text { 25. Percentual em Ocupações da } \\
\text { Agropecuária e da Produção Extra- } \\
\text { tiva Vegetal e Animal }\end{array}$ & 70,22 & 54,85 & 47 & 36,43 \\
\hline & $\begin{array}{l}\text { 26. Percentual em Ocupações da } \\
\text { Produção Extrativa Mineral }\end{array}$ & 0,64 & 0,56 & 0,69 & 0,35 \\
\hline & $\begin{array}{l}\text { 27. Percentual em Ocupações das } \\
\text { Indústrias e Transformação e Cons- } \\
\text { trução Civil }\end{array}$ & 8,2 & 12,98 & 14,48 & 15,02 \\
\hline & $\begin{array}{l}\text { 28. Percentual em Ocupações do Co- } \\
\text { mércio e Atividades Auxiliares }\end{array}$ & 1,97 & 4,58 & 6,31 & 7,88 \\
\hline & $\begin{array}{l}\text { 29. Percentual em Ocupações dos } \\
\text { Transportes e Comunicações }\end{array}$ & 2,53 & 3,05 & 3,29 & 3,61 \\
\hline & $\begin{array}{l}\text { 30. Percentual em Ocupações da } \\
\text { Prestação de Serviços }\end{array}$ & 4,97 & 6,99 & 9,85 & 12,82 \\
\hline & $\begin{array}{l}\text { 31. Percentual em Ocupações da De- } \\
\text { fesa Nacional e Segurança Pública }\end{array}$ & 0,54 & 0,62 & 0,77 & 0,81 \\
\hline \multirow{3}{*}{$\begin{array}{l}\text { 5-Estrutura } \\
\text { Familiar }\end{array}$} & $\begin{array}{l}\text { 32. Percentual de pessoas em famí- } \\
\text { lias com } 5 \text { membros ou mais }\end{array}$ & 72,29 & 66,7 & 30,33 & 23,65 \\
\hline & $\begin{array}{l}\text { 33. Percentual de pessoas em famí- } \\
\text { lias cujos chefes são mulheres }\end{array}$ & 7,87 & 8,95 & 12,42 & 17,08 \\
\hline & $\begin{array}{l}\text { 34. Número médio de filhos por fa- } \\
\text { mília }\end{array}$ & 2,96 & 2,62 & 2,11 & 1,69 \\
\hline
\end{tabular}


Tabela 1 - Continuação

\begin{tabular}{|c|c|c|c|c|c|}
\hline Grupos & Variáveis & 1970 & 1980 & 1991 & 2000 \\
\hline \multirow{9}{*}{$\begin{array}{l}\text { 6-Infra- } \\
\text { Estrutura } \\
\text { Domiciliar }\end{array}$} & $\begin{array}{l}\text { 35. Densidade de moradores por cô- } \\
\text { modo } \\
\text { Percentual de pessoas em domicílios } \\
\text { com: }\end{array}$ & 1,48 & 1,33 & 1,12 & 0,97 \\
\hline & 36. Rede geral de abastecimento & 14,42 & 29,75 & 48,37 & 61,78 \\
\hline & 37. Rede geral de esgoto & 4,79 & 10,39 & 16,76 & 30,42 \\
\hline & 38. Iluminação elétrica & 24,09 & 44,85 & 73,48 & 88,75 \\
\hline & $\begin{array}{l}\text { 39. Densidade de pessoas por dor- } \\
\text { mitório }>2\end{array}$ & 65,2 & 59,94 & 25,25 & 37,69 \\
\hline & 40. Automóvel & 4,63 & 15,5 & 15,52 & 25,96 \\
\hline & 41. Rádio & 49,4 & 73,67 & 76 & 84,28 \\
\hline & 42. Televisão & 6,73 & 32,36 & 69,18 & 79,2 \\
\hline & 43. Geladeira & 9,41 & 27,48 & 61,84 & 70,76 \\
\hline \multirow[t]{4}{*}{$\begin{array}{l}\text { 7- } \\
\text { Rendimentos }\end{array}$} & $\begin{array}{l}\text { 44. Rendimento familiar (total do } \\
\text { rendimento da família excluindo } \\
\text { pensionistas, empregados domésti- } \\
\text { cos e parentes de empregados do- } \\
\text { mésticos) per capita médio (em R\$ } \\
\text { de } 2000 \text { ) }\end{array}$ & 45,64 & 115,56 & 109,73 & 177,14 \\
\hline & $\begin{array}{l}\text { 45. Rendimento individual médio } \\
\text { (em R\$ de 2000) }\end{array}$ & 159,54 & 116,86 & 144,31 & 218,58 \\
\hline & $\begin{array}{l}\text { 46. Total de rendimentos per capita } \\
\text { (Rendimento Total/População) }\end{array}$ & $2.007,6$ & $6.201,22$ & $7.336,24$ & $12.782,08$ \\
\hline & $\begin{array}{l}\text { 47. Total de rendimentos (em mil RS } \\
\text { de } 2000 \text { ) }\end{array}$ & 45,02 & 116,63 & 109,91 & 177,07 \\
\hline \multirow{2}{*}{$\begin{array}{l}\text { 8- } \\
\text { Desigualdade } \\
\text { de Renda }\end{array}$} & $\begin{array}{l}\text { 48. Índice de Gini para rendimento } \\
\text { familiar per capita }\end{array}$ & 0,46 & 0,52 & 0,54 & 0,57 \\
\hline & $\begin{array}{l}\text { 49. Índice de Theil para rendimento } \\
\text { familiar per capita }\end{array}$ & 0,34 & 0,41 & 0,45 & 0,46 \\
\hline
\end{tabular}


Tabela 1 - Continuação

\begin{tabular}{|c|c|c|c|c|c|}
\hline Grupos & Variáveis & 1970 & 1980 & 1991 & 2000 \\
\hline \multirow{9}{*}{ 9-Educação } & $\begin{array}{l}\text { 50. Percentual da população alfabe- } \\
\text { tizada (pessoas que sabem ler ou es- } \\
\text { crever) }\end{array}$ & 51,87 & 58,88 & 66,62 & 70,33 \\
\hline & $\begin{array}{l}\text { 51. Percentual de analfabetos com } \\
15 \text { anos ou mais }\end{array}$ & 43,68 & 36,67 & 29,74 & 20,67 \\
\hline & $\begin{array}{l}\text { 52. Média de anos de estudo da po- } \\
\text { pulação acima de } 10 \text { anos }\end{array}$ & 1,39 & 1,88 & 3,45 & 4,61 \\
\hline & $\begin{array}{l}\text { 53. Média de anos de estudo da po- } \\
\text { pulação de } 15 \text { anos ou mais }\end{array}$ & 1,65 & 2,62 & 3,62 & 4,76 \\
\hline & $\begin{array}{l}\text { 54. Média de anos de estudo da po- } \\
\text { pulação de } 25 \text { anos ou mais }\end{array}$ & 1,33 & 2,09 & 3,16 & 4,16 \\
\hline & $\begin{array}{l}\text { 55. Taxa específica de conclusão do } \\
\text { ensino fundamental (total de pes- } \\
\text { soas com ensino fundamental di- } \\
\text { vidido pela população de } 14 \text { a } 17 \\
\text { anos) }\end{array}$ & 0,22 & 0,64 & 1,25 & 2,26 \\
\hline & $\begin{array}{l}\text { 56. Taxa específica de conclusão do } \\
\text { ensino médio (total de pessoas com } \\
\text { ensino médio dividido pela popula- } \\
\text { ção de } 17 \text { a } 22 \text { anos) }\end{array}$ & 0,07 & 0,19 & 0,46 & 0,79 \\
\hline & $\begin{array}{l}\text { 57. Taxa específica de conclusão } \\
\text { do ensino superior (total de pessoas } \\
\text { com curso superior dividido pela } \\
\text { população acima de } 22 \text { anos) }\end{array}$ & 0 & 0,01 & 0,02 & 0,02 \\
\hline & $\begin{array}{l}\text { 58. Percentual de crianças (po- } \\
\text { pulação de } 7 \text { a } 14 \text { anos) que não } \\
\text { freqüenta escola }\end{array}$ & 60,2 & 41,29 & 25,22 & 5,91 \\
\hline
\end{tabular}

Na dimensão características da população, incluímos variáveis que apresentam a escala populacional do município, a estrutura etária e de gênero, bem como o grau de urbanização. Já a estrutura produtiva apresenta o percentual de ocupados em atividades econômicas classificadas como: agropecuária, extração, indústria, construção civil, comércio e serviços, subdividido em serviços distributivos, produtivos, institucionais, pessoais, de ensino e saúde. No caso da indústria, a mesma é subdividida em dois grupos: tradicional (minerais não metálicos, fumo, alimentação e bebidas, têxtil e vestuário, gráfica, madeira e mobiliário) e moderna (metalúrgicas, mecânicas, material elétrico e comunicação, material de transporte, borracha, papel e papelão, plásticos, químicas, farmacêuticas, derivadas do petróleo e carvão). A caracterização econômica das unidades territoriais é complementada pelas dimensões características do mercado de trabalho e estrutura ocupacional. Para caracterização do mercado de trabalho, temos: a oferta e demanda de trabalho, medida pelas taxas de atividade e ocupação; o grau de formalização ou informalidade das economias, dado pela distribuição percentual de ocupados por posição na ocupação; além do rendimento por trabalhador e do percentual de crianças trabalhando.

Por outro lado, a dimensão estrutura familiar, apresenta as variáveis número médio de filhos e percentual de pessoas em famílias com cinco membros ou mais, que espelham o estágio de transição 
demográfica dos municípios, conforme descrito na literatura de demografia (Heer e Smith, 1968, Cassen, 1978, Kirk, 1996, Mason, 1997). Como opção para retratar as condições de vida da população, consideramos tanto o acesso a serviços públicos básicos, como a bens de consumo duráveis. A restrição para escolha das variáveis dessa dimensão foi a disponibilidade de informações existentes no Censo Demográfico de 1970, daí terem sido incluídos, por exemplo, apenas quatro bens duráveis (automóvel, rádio, televisão, geladeira).

Por fim, a dimensão educação capta a dotação de capital humano, nos seus diferentes níveis, nas unidades territoriais, enquanto que as dimensões rendimento e desigualdade representam tanto a renda média e individual das localidades, medidas em termos totais, per capita e familiar per capita, como também a sua distribuição na população, por meio dos índices de Gini e de Theil.

Assim, procuramos caracterizar as regiões da forma mais ampla possível diante das limitações das bases de dados utilizadas.

\section{METODOLOGIA DE IDENTIFICAÇÃO DE CONGLOMERADOS ESPACIAIS}

O ponto de partida de nossa análise é a definição de regiões espacialmente contíguas que tenham características semelhantes. Para isso, consideramos o conjunto de informações descrito na seção anterior e um modelo estatístico para a análise de cluster. Como estamos interessados em uma análise de convergência entre 1970 e 2000, vamos fazer a regionalização a partir das informações relativas ao ano de 1970 apenas, que é, para nós, o estado inicial dessas economias.

A tarefa fundamental da análise de cluster é a divisão de um conjunto de $n$ objetos em $k(<n)$ clusters de modo que objetos pertencentes a um mesmo agrupamento sejam similares entre si e diferentes dos demais. Essa similaridade é medida em função de um vetor de atributos, os quais constituem o perfil de cada objeto ou unidade de análise (Maravalle e Simeone, 1997).

Diferentemente da análise de cluster tradicional, em estatística espacial, impõe-se uma restrição de contiguidade, ou seja, considera-se a localização das observações no espaço geográfico, logo, além de possuírem atributos semelhantes, os objetos de uma mesma aglomeração devem apresentar uma fronteira geográfica comum.

A identificação desses conglomerados espaciais dá origem ao procedimento da regionalização. Existem várias técnicas de análise estatística, como os índices de autocorrelação e os diagramas de Voronoi, ou mesmo considerações subjetivas que podem ser utilizadas para a regionalização de áreas. O método utilizado neste artigo fundamenta-se no trabalho de Maravalle e Simeone (1995), que propõem a transformação do mapa geográfico em um grafo de contigüidade espacial e a sua redução a uma árvore geradora.

Um grafo é simplesmente um conjunto de vértices, ou nós, que são ligados por arestas. A transformação do mapa do Brasil em um grafo é a representação de cada um dos centróides dos municípios como sendo um nó que se liga ao centróide do município vizinho (que possui uma fronteira geográfica comum) por uma aresta. Já a árvore geradora é um grafo conexo, em que existe um e apenas um caminho que liga quaisquer dois nós, além disso, o número de arestas é igual ao número de nós menos um, de modo que, ao se apagar qualquer uma das arestas, subdivide-se o grafo em dois subgrafos não conectados.

Como método de redução da árvore geradora, é adotada a opção de Assunção et alii (2002). ${ }^{5}$ Os autores utilizam a árvore geradora mínima para fazer a redução do grafo, particionando, a partir daí, sucessivamente a árvore para obter a regionalização desejada, seja em função do número de grupos ou do tamanho mínimo da população de cada grupo ou conglomerado, ${ }^{6}$ como será apresentado a seguir.

\footnotetext{
${ }^{5}$ Essa solução está implementada nos softwares SKATER e Terraview 3.0 plus(C).

${ }^{6}$ É importante salientar que a metodologia parte da definição de um grafo conexo, o que só é possível obter caso se tenha um mapa sem ilhas. Especificamente, no caso do mapa do Brasil, considerando-se as unidades territoriais de análise, formadas
} 
Aqui, as $n$ áreas geográficas contíguas, organizadas na forma de um mapa, são as 3948 unidades territoriais de análise para o Brasil, pertencentes à malha municipal compatibilizada descrita na seção anterior e da qual excluímos as duas unidades ilhas, Fernando de Noronha e Ilhabela. À cada uma dessas unidades territoriais $i, i=1,2, \ldots, 3948$, associamos um vetor $x_{i}$ de características quantitativas que definem o perfil dessa área. Tais características devem estar devidamente padronizadas para que aquelas com maior variância não dominem o valor da dissimilaridade.

Assim, para construção dos vetores $x_{i}$, a partir das variáveis descritas na Tabela 1 , realizamos uma análise de componentes principais para resumir as informações contidas nas 58 variáveis para o ano de 1970 em um número menor de componentes, de modo a facilitar o cálculo das dissimilaridades entre as unidades territoriais de análise. Basicamente, o argumento da análise de componentes principais é que as variáveis podem ser agrupadas segundo as suas correlações, dando origem a novas variáveis, chamadas componentes (Johnson e Wichern, 2002). Os componentes são, portanto, variáveis construídas, responsáveis pelas correlações observadas.

No caso da base de dados utilizada nesse artigo, o objetivo de se adotar a análise multivariada é construir componentes que expressem cada uma das nove dimensões, apresentadas na Tabela 1, que caracterizam o estado inicial, em 1970, de desenvolvimento ou estagnação. Como as variáveis adotadas possuem unidades de medidas e variância bastante distintas, ao invés de se utilizar as variáveis na sua forma original, procede-se a uma padronização das mesmas, com o intuito de se evitar que a variável com maior variância influencie mais fortemente a composição dos auto vetores.

Para não misturarmos indicadores fundamentalmente diferentes, como, por exemplo, acesso à abastecimento de água adequado e analfabetismo, a criação dos componentes via análise multivariada foi realizada, separadamente para cada uma das dimensões da Tabela 1. Assim, ao invés de chegarmos ao indicador síntese de desenvolvimento, nos moldes do IDH (Índice de Desenvolvimento Humano), desenvolvido pelas Nações Unidas, preservamos a multidimensionalidade inicial, o que irá nos permitir chegar a um grau de homogeneidade maior, levando em conta às semelhanças das unidades territoriais de análise em cada uma das nove dimensões levantadas.

A Tabela 2 apresenta, juntamente com as variáveis incluídas em cada um dos vetores de atributos, os componentes resultantes da análise multivariada e o percentual da variância explicada por essas variáveis hipotéticas não observadas.

Uma vez definidos os nós do grafo para o Brasil como sendo os centróides das 3948 unidades territoriais de análise e construídos os vetores de atributos $x_{i}$ para cada um desses nós, a partir da análise de componentes principais, o passo seguinte é associar, a cada uma das arestas que ligam os 3948 nós, um custo. Tal custo é definido com base no grau de dissimilaridade dos perfis entre as duas áreas, de modo que quanto mais diferentes forem duas áreas, maior será este custo. Para a nossa análise, será considerada a distância euclidiana entre os vetores de atributos, constituídos pelos 19 componentes de cada unidade territorial de análise, resultantes da análise multivariada. Assim, o custo da aresta entre uma unidade territorial $i$ e $k$ é dado por:

$$
\operatorname{Custo}(i, k)=\sqrt{\sum_{j=1}^{19}\left(x_{i j}-x_{k j}\right)^{2}}
$$

onde $i$ e $k$, denotam duas unidades territoriais de análise diferentes, e, $j$, variando de 1 até 19 , refere-se aos componentes principais que formam o vetor de características quantitativas $\left(x_{i}\right)$ de cada unidade territorial de análise.

A árvore geradora mínima será aquela constituída pelo grafo de menor custo, isto é, em que o somatório dos custos das arestas seja mínimo. Para construir tal árvore, Assunção et alii (2002) utilizam

com base nos municípios existentes em 1970, existem duas ilhas, constituídas pelos municípios de Ilhabela (SP) e de Fernando de Noronha (PE). Nesse caso, é necessário definir vizinhos para esses municípios ou excluí-los da amostra, o que foi feito no procedimento de identificação dos conglomerados espaciais, tendo em vista às restrições do programa de computador utilizado.

RBE Rio de Janeiro v. 61 n. $3 /$ p. $301-330 \quad$ Jul-Set 2007 
Tabela 2 - Análise de Componente Principal

\begin{tabular}{|c|c|c|c|}
\hline Vetores & $\begin{array}{l}\text { Variância } \\
\text { Explicada } \\
(\%)\end{array}$ & Fatores & Variáveis-Tabela 1 \\
\hline $\begin{array}{l}\text { 1.Características } \\
\text { da População }\end{array}$ & 90,56 & $\begin{array}{l}\text { Pop1 Estrutura Etária } \\
\text { Pop2 Gênero } \\
\text { Pop3 Tamanho } \\
\text { Pop4 Urbanização }\end{array}$ & Variável 1 a 7 \\
\hline 2.Estrutura Produtiva & 52,98 & $\begin{array}{l}\text { Ep1 Menos Agropecuária } \\
\text { Ep2 Indústria Extrativa } \\
\text { Ep3 Menos Indústria }\end{array}$ & $\begin{array}{l}\text { Variáveis de Estrutura } \\
\text { Produtiva de } 8 \text { a } 14\end{array}$ \\
\hline $\begin{array}{l}\text { 3.Características do Mer- } \\
\text { cado de Trabalho }\end{array}$ & 81,56 & $\begin{array}{l}\text { Trab1 Rendimento por trabalhador, } \\
\text { emprego e trabalho infantil } \\
\text { Trab2 Emprego Formal } \\
\text { Trab3 Empregadores }\end{array}$ & Variável 15 a 22 \\
\hline 4.Estrutura Ocupacional & 63,32 & $\begin{array}{l}\text { Eo1 Ocupações em setores não- } \\
\text { primários } \\
\text { Eo2 Ocupações Produção Extrativa } \\
\text { Mineral } \\
\text { Eo3 Ocupações Defesa Nacional e } \\
\text { Segurança Pública }\end{array}$ & $\begin{array}{l}\text { Variáveis de Estrutura } \\
\text { Ocupacional de } 23 \text { a } 31\end{array}$ \\
\hline 5.Estrutura Familiar & 97,65 & $\begin{array}{l}\text { Fam1 Tamanho da Família } \\
\text { Fam2 Chefes de Família }\end{array}$ & Variáveis 32 a 34 \\
\hline 6.Infra-Estrutura Domiciliar & 64,93 & $\begin{array}{l}\text { Ied1 Acesso a Infra-estrutura Domi- } \\
\text { ciliar }\end{array}$ & Variáveis 35 a 43 \\
\hline 7.Rendimentos & 75,11 & Rend1 Rendimento & Variáveis 44 a 37 \\
\hline 8.Desigualdade & 95,06 & Des1 Desigualdade & Variáveis 48 e 49 \\
\hline 9.Educação & 80,7 & Edu1 Educação & Variáveis 50 a 58 \\
\hline
\end{tabular}

Fonte: Elaboração própria.

o algoritmo de Prim (1957), que constrói a árvore geradora mínima de forma recursiva. Partindo de um nó inicial, adiciona-se a aresta de menor custo, dando origem a uma árvore $T 1$, em seguida busca a aresta de menor custo que una o nó em $T 1$ a outro que não esteja em $T 1$, formando a árvore $T 2$, na seqüência é adicionada uma aresta que ligue um nó de $T 2$ a outro nó fora de $T 2$, tendo como resultado uma árvore $T 3$, isso é feito sucessivas vezes até que tenham sido adicionadas $n-1$ arestas e seus respectivos nós terminais. No nosso caso, tratando-se de 3948 unidades territoriais de análise, repete-se o algoritmo até que tenham sido adicionadas 3947 arestas.

Uma vez construída a árvore geradora mínima, procede-se à partição da mesma, com o intuito de se obter os conglomerados espaciais. A lógica é semelhante à da etapa anterior, retirar, sucessivamente, arestas de maior custo, de modo a se ter subgrafos desconectados, internamente homogêneos. Serão escolhidas, desse modo, $k-1$ arestas para se obter $k$ regiões.

Contudo, caso fosse adotado o mesmo critério de custo da etapa anterior, a tendência seria retirar as últimas arestas adicionadas na árvore geradora mínima, que, não por acaso, tendem a ligar áreas isoladas no grafo. Para evitar o problema de, ao se apagar uma aresta, gerar um conglomerado formado por poucas áreas e outro com o restante das áreas, Assunção et alii (2002) propõem uma definição alternativa de custo. Segundo a proposição dos autores, o custo de se apagar uma aresta l qualquer é dado pela diferença entre (a) e (b):

(a) a soma dos quadrados dos desvios no espaço das variáveis em relação à média de todas as áreas da árvore; ou seja, para as unidades territoriais do Brasil e atributos aqui considerados, tem-se: 


$$
\text { Soma dos Quadrados dos Desvios }=\sum_{j=1}^{19} \sum_{i=1}^{3948}\left(x_{i j}-\bar{x}_{j}\right)^{2}
$$

onde $\bar{x}_{j}=\sum_{i=1}^{3948} \frac{x_{i j}}{3948}$.

(b) a soma das duas parcelas obtidas da soma dos quadrados dos desvios das duas sub-árvores formadas pela retirada da aresta $l$, ou seja, consideram-se apenas os atributos referentes aos objetos pertencentes a cada uma das duas sub-árvores geradas. Quanto menor for essa soma, mais homogêneos serão os conglomerados resultantes.

Com base nessas definições, o que se faz é eliminar a aresta com o maior custo de se apagar, criando duas regiões, em seguida, repete-se o procedimento dentro de cada conglomerado resultante e apagase a aresta de maior custo de apagar entre aquelas dos dois conglomerados. 0 algoritmo é finalizado quando tiverem sido criadas as $k(<n)$ regiões desejadas.

A seção seguinte apresenta os resultados da aplicação dessa metodologia para regionalização das 3948 unidades territoriais de análise do Brasil, segundo os vetores de atributos compostos pelos 19 componentes apresentados na Tabela 2.

\section{RESULTADOS}

\subsection{Identificação das Regiões}

Considerando-se o perfil das 3948 unidades territoriais de análise, composto pelos 19 fatores da Tabela 2, é possível, por meio da metodologia descrita anteriormente, gerar uma regionalização para o Brasil de modo a se agregar municípios que sejam similares em termos de estágio de desenvolvimento em 1970, de forma a não nos atermos às divisões administrativas de macrorregiões, Unidades da Federação ou microrregiões.

Como critério de parada para partição da árvore geradora mínima definimos a criação de 400 conglomerados, o que corresponde a pouco mais de $10 \%$ do total de unidades territoriais de análise consideradas. Foram gerados grupamentos de municípios como as microrregiões geográficas do IBGE, com a diferença de que o nosso critério é o de maior homogeneidade possível quanto aos componentes relacionados ao estado inicial de desenvolvimento em 1970. De outro lado, o método de partição da árvore geradora mínima empregado permite que algumas regiões sejam formadas por um só município nos casos de dissimilaridade acentuada com sua vizinhança, é o que ocorre, por exemplo, com cidades como São Paulo, Rio de Janeiro, Belo Horizonte, entre outras. Tal fato é uma vantagem para a análise de convergência, já que as capitais, reconhecidamente, apresentam uma dinâmica bastante distinta de seu entorno.

A Figura 1 apresenta a regionalização final obtida. Embora seja difícil a identificação visual das quatrocentas regiões encontradas, é possível verificar que o resultado é um grande mosaico de regiões, onde se tem, inclusive, a partição do Norte e do Nordeste em vários conglomerados.

Os resultados da regionalização sugerem, ainda, que a questão do desenvolvimento não deve ser tratada segundo a ótica dos limites territoriais administrativos, ou seja, em termos de macrorregião, Unidade da Federação ou microrregião, o que torna ainda mais complexa a formulação de políticas públicas nessa área.

\subsection{Classificação das Regiões}

Uma vez realizada a regionalização, o problema seguinte é definir um critério de hierarquia para tais regiões, de modo a verificar os dois extremos: as regiões mais e menos desenvolvidas, considerando o seu estágio inicial em 1970. Como ampliar uma análise de desenvolvimento baseada em renda para uma análise multidimensional? Como justificar as variáveis consideradas nessa hierarquia? 


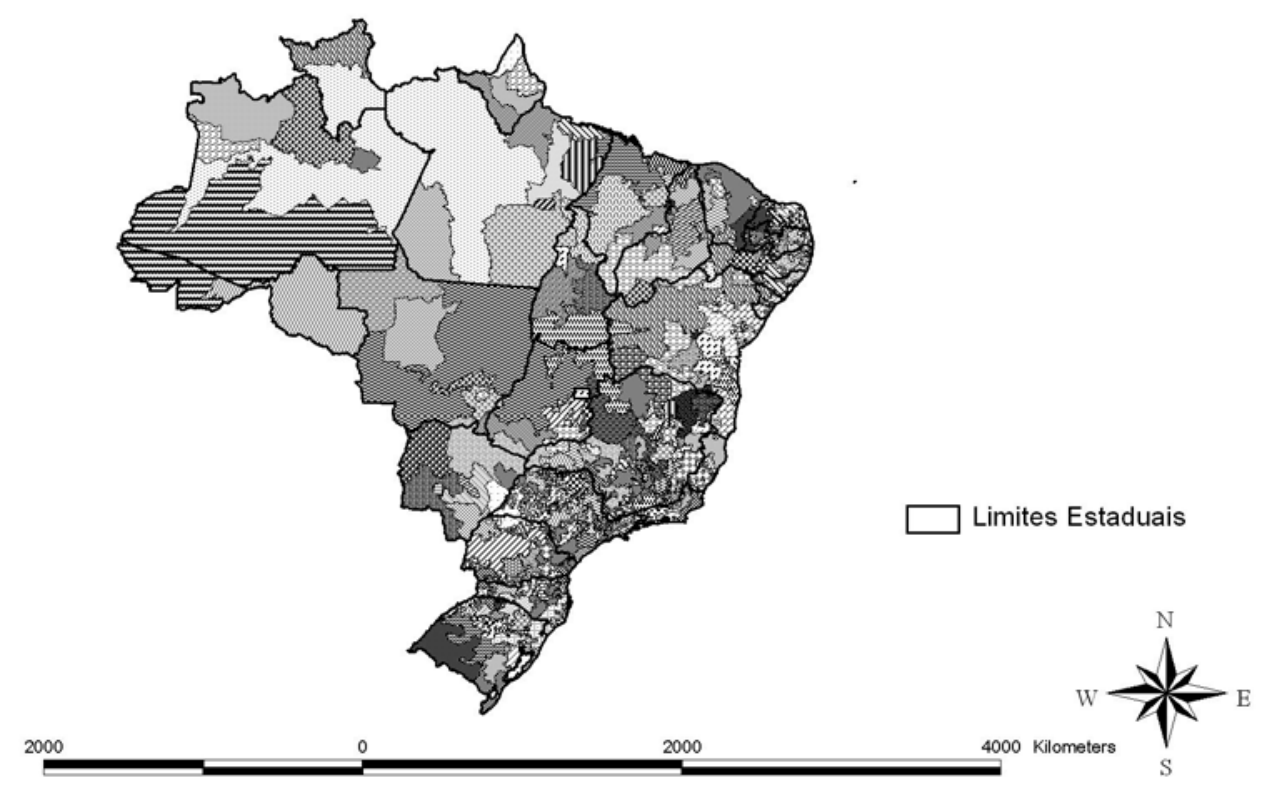

Fonte: Elaboração Própria.

A alternativa utilizada para hierarquização das regiões fundamenta-se nos componentes principais resultantes da análise multivariada das variáveis da Tabela 1. Foram consideradas, seguindo a ótica de associação entre desenvolvimento e condições de vida da população, cinco dimensões: características do trabalho (componente rendimento por trabalhador, emprego e trabalho infantil e componente emprego formal); estrutura familiar (componente tamanho da família); infra-estrutura domiciliar; educação e renda.

Na dimensão características do mercado de trabalho, o componente rendimento por trabalhador, emprego e trabalho infantil e o componente emprego formal representam o grau de desenvolvimento do mercado de trabalho e estão fortemente associados a transformações estruturais na economia, notadamente a passagem de uma economia agrária para uma economia urbana. No meio rural, grande parte das pessoas trabalham para o auto-consumo ou como conta-própria, sem as proteções das leis trabalhistas, que atuam mais fortemente do mercado de trabalho formal urbano, além disso, o trabalho infantil, a exemplo do que ocorre nas periferias das grandes cidades, tende a ter uma participação importante na renda familiar. Em contraste com o setor formal urbano, os setores urbano informal e rural oferecem menores salários que flutuam segundo a oferta e demanda de mão-de-obra, diante da ausência de pressões sindicais e de dificuldades de implementação de políticas governamentais de proteção ao trabalhador (Harris e Todaro, 1970).

O componente tamanho das famílias, por sua vez, funciona como proxy para as taxas de fecundidade. Fishlow (1972) destaca que, no Brasil, 29\% das famílias eram compostas, entre as décadas de 1960 e 1970, por seis ou mais indivíduos, sendo que mais da metade destas estavam abaixo da linha de pobreza.

O componente de infra-estrutura domiciliar, assim como o componente tamanho da família, foi selecionado dada a sua associação com os diferentes níveis de pobreza. A posse de bens duráveis, 
bem como a condição de moradia das famílias, funciona como uma proxy para a riqueza familiar. De outro lado, o percentual de residentes em domicílios com acesso a serviços públicos de infra-estrutura básica dá também uma dimensão das condições sanitárias da unidade territorial de análise, que são fortemente correlacionadas com as taxas de mortalidade e estado de saúde dos indivíduos, dimensão para qual os Censos Demográficos não apresentam informações.

Já o componente educação representa o acúmulo de capital humano nas unidades territoriais de análise, cuja associação com maior nível de desenvolvimento aparece claramente na literatura sobre capital humano, do ponto de vista individual (Becker, 1991) ou das teorias de crescimento endógeno (Mankiw, Romer e Weil, 1992). Juntamente com o componente rendimento por trabalhador, emprego e trabalho infantil, dá uma noção das decisões familiares sobre investir ou não em educação das crianças vis-à-vis o papel do trabalho infantil e suas conseqüências, conforme amplamente discutido pela literatura econômica (Basu, 1999, Basu e Van, 1998).

Por fim, o componente renda refere-se à caracterização de desenvolvimento sob a ótica mais freqüente na literatura econômica, qual seja: o crescimento econômico.

As dimensões características da população, estrutura produtiva, estrutura ocupacional e urbanização não foram incluídas na hierarquização, mas são consideradas na etapa seguinte para caracterização das regiões mais e menos desenvolvidas e análise de convergência multidimensional.

Assim, o primeiro passo para a identificação das regiões que pudessem ser consideradas como menos e mais desenvolvidas em 1970 foi gerar valores médios dos componentes: rendimento por trabalhador, emprego e trabalho infantil; emprego formal; tamanho da família; acesso à infra-estrutura domiciliar; rendimento e educação, considerando as unidades territoriais de análise pertencentes a cada região. Em seguida, as regiões foram hierarquizadas, das mais para as menos desenvolvidas, segundo cada um dos componentes em separado. Por fim, foram consideradas mais desenvolvidas as vinte regiões com menor somatório desses ranks por componentes. São Paulo, por exemplo, a região mais desenvolvida segundo a nossa hierarquia, foi a nona colocada no componente rendimento por trabalhador, emprego e trabalho infantil, a décima oitava em emprego formal, a primeira colocada nos componentes tamanho da família, infra-estrutura domiciliar e renda, e a sétima em educação. O somatório desses ranks gera um total de 37. A segunda localidade de maior desenvolvimento, Niterói, apresenta um somatório dos ranks igual a 49. Analogamente, as vinte regiões com maior somatório foram definidas como as de menor desenvolvimento. A Região de Catolândia e Cristópolis, na Bahia, a de menor desenvolvimento na nossa hierarquia, foi a $246^{\mathrm{a}}$. colocada no ranking de rendimento por trabalhador, emprego e trabalho infantil, a $376^{\mathrm{a}}$. no emprego formal, a $400^{\mathrm{a}}$. nos componentes tamanho da família e renda, a $380^{\mathrm{a}}$. na infra-estrutura domiciliar e a 399 . em educação, totalizando uma soma de ranks igual a 2200.

A Figura 2 representa, em cinza, as vinte regiões com os piores resultados conjuntos para os indicadores de trabalho, estrutura familiar, infra-estrutura domiciliar, renda, e educação, aqui, consideradas, como de menor desenvolvimento. Por esse mapa, verifica-se que todas essas regiões de menor desenvolvimento estão localizadas na Região Nordeste e no Estado de Minas Gerais.

De outro lado, entre as regiões em preto (20), enquadradas como mais desenvolvidas, oito são capitais, incluindo uma na região Nordeste e outra no Norte (São Paulo, Belo Horizonte, Rio de Janeiro, Goiânia, Florianópolis, Curitiba, Salvador, Belém). Ademais, entre estas vinte regiões mais desenvolvidas, cinco regiões localizam-se no Estado de São Paulo e quatro no Rio de Janeiro, destacando-se, além das capitais, as regiões de Santos, de Itatiba, Jundiaí, Valinhos e Vinhedo, em São Paulo e de Niterói e Volta Redonda, no Rio de Janeiro, entre outras.

A Tabela 3 apresenta a identificação dessas regiões, com os valores de população, área e densidade demográficas, segundo o Censo Demográfico de 2000 (IBGE).

Pela Tabela 3 verifica-se que as 20 regiões menos desenvolvidas ocupam uma área 334\% maior do que a das regiões de maior desenvolvimento.

No caso da população total, as regiões de menor desenvolvimento em 1970, passados trinta anos, permanecem abrigando uma parcela reduzida da população, em torno de $3 \%$ da população residente no 
Figura 2 - Brasil - Regiões Selecionadas

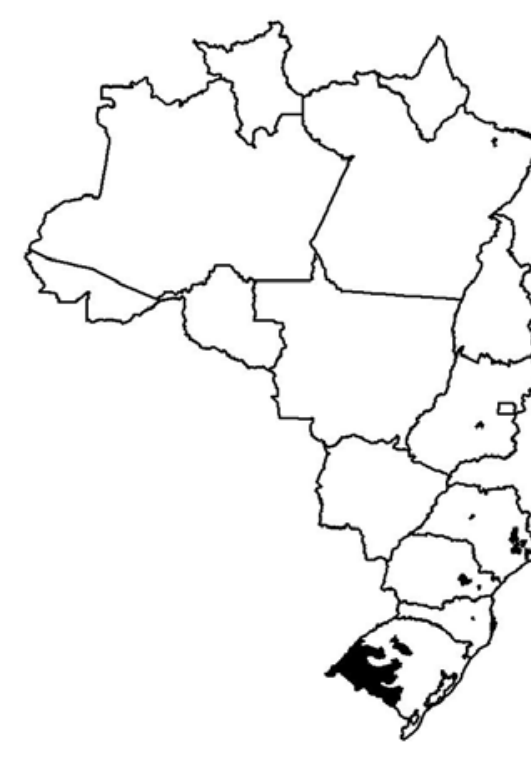

2000
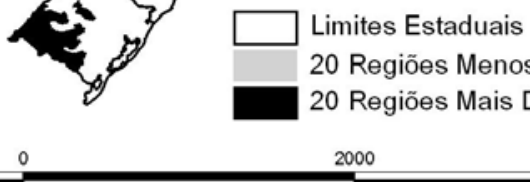

20 Regiões Menos Desenvolvidas

\20 Regiões Mais Desenvolvidas
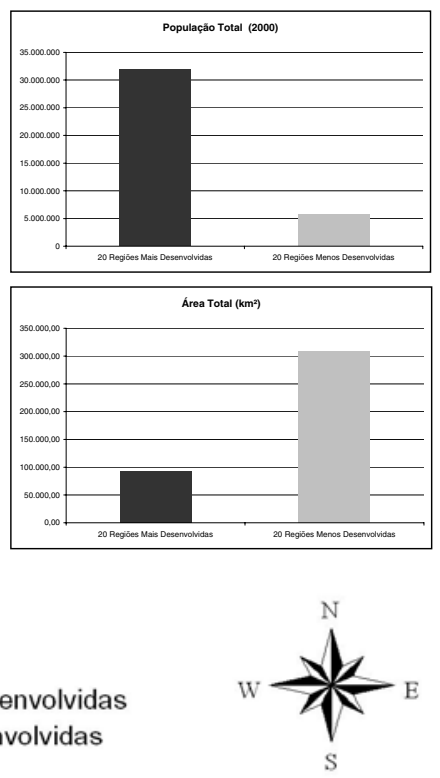

2000

4000 Kilometers

Fonte: Elaboração Própria.

Brasil, contra uma população de 31.341 .305 residente nas vinte regiões mais desenvolvidas $(18,80 \%$ da população total do país).

Conseqüentemente, como esperado, a densidade populacional, nas 20 regiões mais desenvolvidas, chega a 346,84 habitantes por quilômetro quadrado, ao passo que, nas áreas classificadas como de menor desenvolvimento, a densidade fica ao redor de 18,46 habitantes por quilômetro quadrado, bem próxima ao valor para o Brasil $(19,99)$.

Considerando as vinte regiões mais desenvolvidas, temos um conjunto de conglomerados espaciais caracterizados por: a) rendimentos per capita mais elevados, comparativamente ao restante do Brasil; b) elevado percentual de pessoas em domicílios com serviços públicos de infra-estrutura adequada, especialmente de abastecimento e esgotamento sanitário; c) elevados valores de rendimentos por trabalhadores; d) uma grande concentração de ocupados no setor de serviços, chegando a mais de $50 \%$ em nove municípios dessas regiões; e) mais de 70\% de ocupados como empregados na média e, f) média de anos de estudo acima de 6 anos para a população com vinte e cinco anos ou mais.

Já as regiões de menor desenvolvimento apresentam: a) rendimentos per capita muito baixos; b) condições de infra-estrutura domiciliar mais precárias, especialmente no que se refere ao esgotamento sanitário; c) média inferior de rendimento por trabalhador; d) elevado percentual de ocupados no setor de agropecuária (o percentual médio se mantém acima de 50\%, no ano 2000, em 176 municípios dos 328 que compõem as vinte regiões) e, conseqüentemente, taxas menores de urbanização; e) percentual alto de pessoas ocupadas como conta-própria e sem remuneração (em termos relativos); f) média de anos de estudo bastante inferior ao valor encontrado para o Brasil.

Tais resultados confirmam algumas hipóteses da literatura econômica em termos de transformação estrutural. $\mathrm{O}$ deslocamento da população do campo para a cidade é propiciado por mudanças estrutu- 
Tabela 3 - Regiões Mais Desenvolvidas e Regiões Menos Desenvolvidas - Brasil

\begin{tabular}{|c|c|c|c|}
\hline Região & População & Área $\left(\mathrm{km}^{2}\right)$ & Densidade Demográfica \\
\hline 20 Regiões Mais Desenvolvidas & 31.941 .305 & 92.092 & 346,84 \\
\hline 1.São Paulo (São Paulo) & 10.435 .546 & $1.531,21$ & $6.815,23$ \\
\hline 2.Niterói (Rio de Janeiro) & 459.451 & 135,04 & $3.402,33$ \\
\hline 3.Belo Horizonte (Minas Gerais) & 2.238 .526 & 331,35 & $6.755,77$ \\
\hline 4.Rio de Janeiro (Rio de Janeiro) & 5.857 .904 & $1.267,95$ & $4.619,98$ \\
\hline 5.Santos (São Paulo) & 448.022 & 775,25 & 577,91 \\
\hline 6.Goiânia (Goiás) & 1.151 .083 & $1.128,35$ & $1.020,15$ \\
\hline 7.Lins (São Paulo) & 65.952 & 574,33 & 114,83 \\
\hline 8.Florianópolis (Santa Catarina) & 342.315 & 446,66 & 766,39 \\
\hline 9.Volta Redonda (Rio de Janeiro) & 242.063 & 179,67 & $1.347,26$ \\
\hline 10.São Gonçalo (Rio de Janeiro) & 891.119 & 249,21 & $3.575,78$ \\
\hline $\begin{array}{l}\text { 11.Região de Itatiba, Jundiaí, Valinhos e Vinhedo (São } \\
\text { Paulo) }\end{array}$ & 534.782 & 987,83 & 541,37 \\
\hline 12.Rio do Sul (Santa Catarina) & 51.650 & 261,44 & 197,56 \\
\hline $\begin{array}{l}\text { 13.Região de Campanha, Santa Maria e Santiago (Rio } \\
\text { Grande do Sul) }\end{array}$ & 1.057 .651 & $69.044,31$ & 15,32 \\
\hline 14.Curitiba (Paraná) & 1.587.315 & 432,75 & $3.667,97$ \\
\hline 15.São Lourenço (Minas Gerais) & 36.927 & 56,31 & 655,78 \\
\hline 16.Salvador (Bahia) & 2.455 .143 & 334,89 & $7.331,19$ \\
\hline 17.Belém (Pará) & 1.280 .614 & $1.073,67$ & $1.192,74$ \\
\hline 18.Região de Campinas e Piracicaba (São Paulo) & 2.346 .570 & $5.544,87$ & 423,2 \\
\hline 19.Ponta Grossa (Paraná) & 288.476 & $2.719,22$ & 106,09 \\
\hline 20.Região de Ijuí e Cruz Alta (Rio Grande do Sul) & 170.196 & $5.018,17$ & 33,92 \\
\hline 20 Regiões Menos Desenvolvidas & 5.688 .818 & 308.221 & 18,46 \\
\hline 381.Centro-Sul da Bahia e Jequitinhonha-Mucuri & 744.450 & $35.739,51$ & 20,83 \\
\hline $\begin{array}{l}\text { 382.Parte do Centro-Sul baiano, Norte de Minas e Vale do } \\
\text { São Francisco }\end{array}$ & 384.008 & $34.417,60$ & 11,16 \\
\hline 383.Parte do Norte, Centro-Sul e Sertões Cearenses & 389.927 & $24.536,59$ & 15,89 \\
\hline 384.Sertões Paraibano e Pernambucano & 165.048 & $5.831,49$ & 28,3 \\
\hline 385.Ipecaetá (Bahia) & 18.696 & 394,1 & 47,44 \\
\hline $\begin{array}{l}\text { 386.Região de Vitória da Conquista, Jequié e Arredores } \\
\text { (Bahia) }\end{array}$ & 603.207 & $37.045,93$ & 16,28 \\
\hline 387.Região de Piripá e Tremedal & 54.492 & $3.563,15$ & 15,29 \\
\hline $\begin{array}{l}\text { 388.Região de Limoeiro do Norte, Russas e São João do Ja- } \\
\text { guaribe }\end{array}$ & 115.590 & $2.673,68$ & 43,23 \\
\hline 389.Região de Guarabira e Brejo Paraibano & 115.523 & 740,24 & 156,06 \\
\hline $\begin{array}{l}\text { 390.Região do Centro e Oeste Potiguar (Rio Grande do } \\
\text { Norte) }\end{array}$ & 191.323 & $9.718,74$ & 19,69 \\
\hline 391.Região de Ingá e Serra Redonda (Paraíba) & 28.728 & 348,96 & 82,32 \\
\hline 392.Região do Leste Maranhense e Sudoeste do Piauí & 332.101 & $45.984,29$ & 7,22 \\
\hline 393.Região do Agreste de Itabaiana e Carira (Sergipe) & 126.560 & $1.272,71$ & 99,44 \\
\hline 394.Região de Boquira e Entorno & 338.087 & $31.198,99$ & 10,84 \\
\hline $\begin{array}{l}\text { 395.Região da Mata Paraibana e Pernambucana e Baía For- } \\
\text { mosa (Rio Grande do Norte) }\end{array}$ & 568.771 & $5.754,77$ & 98,83 \\
\hline 396.Parte do Jequitinhonha e Norte de Minas & 98.900 & $12.339,68$ & 8,01 \\
\hline $\begin{array}{l}\text { 397.Região de Chorrochó, Glória, Macururé e Rodelas } \\
\text { (Bahia) }\end{array}$ & 39.602 & $8.815,20$ & 4,49 \\
\hline 398.Região do Oeste Potiguar e Sertão Paraibano & 1.189 .697 & $38.333,04$ & 31,04 \\
\hline $\begin{array}{l}\text { 399.Região de Borborema e Entorno (Paraíba/Rio Grande } \\
\text { do Norte) }\end{array}$ & 168.354 & $8.007,51$ & 21,02 \\
\hline 400.Região de Catolândia e Cristópolis (Bahia) & 15.754 & $1.504,97$ & 10,47 \\
\hline Brasil & 169.872 .856 & $8.498 .698,00$ & 19,99 \\
\hline
\end{tabular}

Fonte: Elaboração Própria, a partir dos microdados do Censo Demográfico, 2000. 
Tabela 4 - Média de Indicadores Selecionados (2000) para as Regiões Mais e Menos Desenvolvidas

\begin{tabular}{|c|c|c|c|}
\hline Indicadores Selecionados & $\begin{array}{l}20 \text { Regiões Mais De- } \\
\text { senvolvidas }\end{array}$ & $\begin{array}{l}20 \text { Regiões Menos De- } \\
\text { senvolvidas }\end{array}$ & $\begin{array}{l}\text { Todas as Re- } \\
\text { giões }\end{array}$ \\
\hline Rendimento per capita & 387,09 & 84,04 & 176,91 \\
\hline $\begin{array}{l}\text { Percentual de Residentes em Domicílios com } \\
\text { Rede Geral de Abastecimento }\end{array}$ & 90,28 & 51,53 & 61,78 \\
\hline $\begin{array}{l}\text { Percentual de Residentes em Domicílios com } \\
\text { Rede Geral de Esgotamento Sanitário }\end{array}$ & 63,57 & 15,84 & 30,43 \\
\hline $\begin{array}{l}\text { Percentual de Residentes em Domicílios com } \\
\text { Iluminação Elétrica }\end{array}$ & 99,06 & 79,08 & 88,75 \\
\hline Rendimento por Trabalhador & 945,39 & 254,45 & 455,83 \\
\hline $\begin{array}{l}\text { Percentual de Ocupados na Agropecuária e Ex- } \\
\text { trativismo }\end{array}$ & 7,62 & 49,7 & 38,79 \\
\hline Percentual de Ocupados em Serviços & 42,38 & 26,24 & 29,36 \\
\hline Percentual de Ocupados na Indústria & 24,2 & 9,48 & 14,36 \\
\hline Percentual de Ocupados como Empregados & 73,01 & 49,17 & 59,48 \\
\hline Percentual de Ocupados como Conta-Própria & 21,3 & 24,13 & 24,99 \\
\hline Percentual de Ocupados sem Remuneração & 2,03 & 25,7 & 13,49 \\
\hline Média de Anos de Estudo & 6,77 & 3,43 & 4,68 \\
\hline $\begin{array}{l}\text { Média de Anos de Estudo da População com } 25 \\
\text { anos ou Mais }\end{array}$ & 6,65 & 2,89 & 4,24 \\
\hline Percentual da População Urbana & 92,98 & 50,67 & 63,16 \\
\hline
\end{tabular}

Fonte: Elaboração Própria a partir de dados do Censo Demográfico 2000 (IBGE)

rais que, juntamente com os incrementos populacionais, geram ganhos de produtividade por trabalhador e aumento da renda per capita associados ao crescimento econômico (Kuznets, 1966). Desse modo, é, à medida que são gerados excedentes na agricultura e desenvolvidos sistemas de transporte, possibilitando a utilização do excedente no comércio, que torna-se possível o aparecimento dos chamados centros urbanos (Bairoch, 1988). Os nossos resultados mostram que as regiões menos desenvolvidas possuem um grande percentual de pessoas residindo no meio rural, trabalhando no setor primário, em sua maioria como conta-própria, com rendimentos mais baixos comparativamente a média, quando se consideram todas as unidades territoriais de análise.

Uma vez identificadas as regiões de maior e menor desenvolvimento, a seção seguinte, volta-se para a análise de convergência entre diversos indicadores de desenvolvimento que caracterizam a estrutura das economias locais.

\subsection{Análise Comparativa das Regiões: há sinais de convergência?}

A seção anterior estabelece as 20 regiões mais desenvolvidas e as 20 regiões menos desenvolvidas, com base nos atributos de rendimento por trabalhador, emprego e trabalho infantil, emprego formal, tamanho da família, infra-estrutura domiciliar, educação e rendimento. Comparando esses dois grupos de regiões, esta seção avalia se há ou não sinais de convergência no processo de desenvolvimento da economia brasileira entre 1970 e 2000.

Para tanto, é realizada uma análise comparativa de algumas das variáveis, apresentadas na Tabela 1, entre as regiões vistas como mais desenvolvidas e aquelas de baixo desenvolvimento. Analisando alguns indicadores sócio-econômicos, para os anos censitários de 1970 a 2000, verificam-se grandes diferenças entre os dois grupos de regiões apresentados na Tabela 3. 


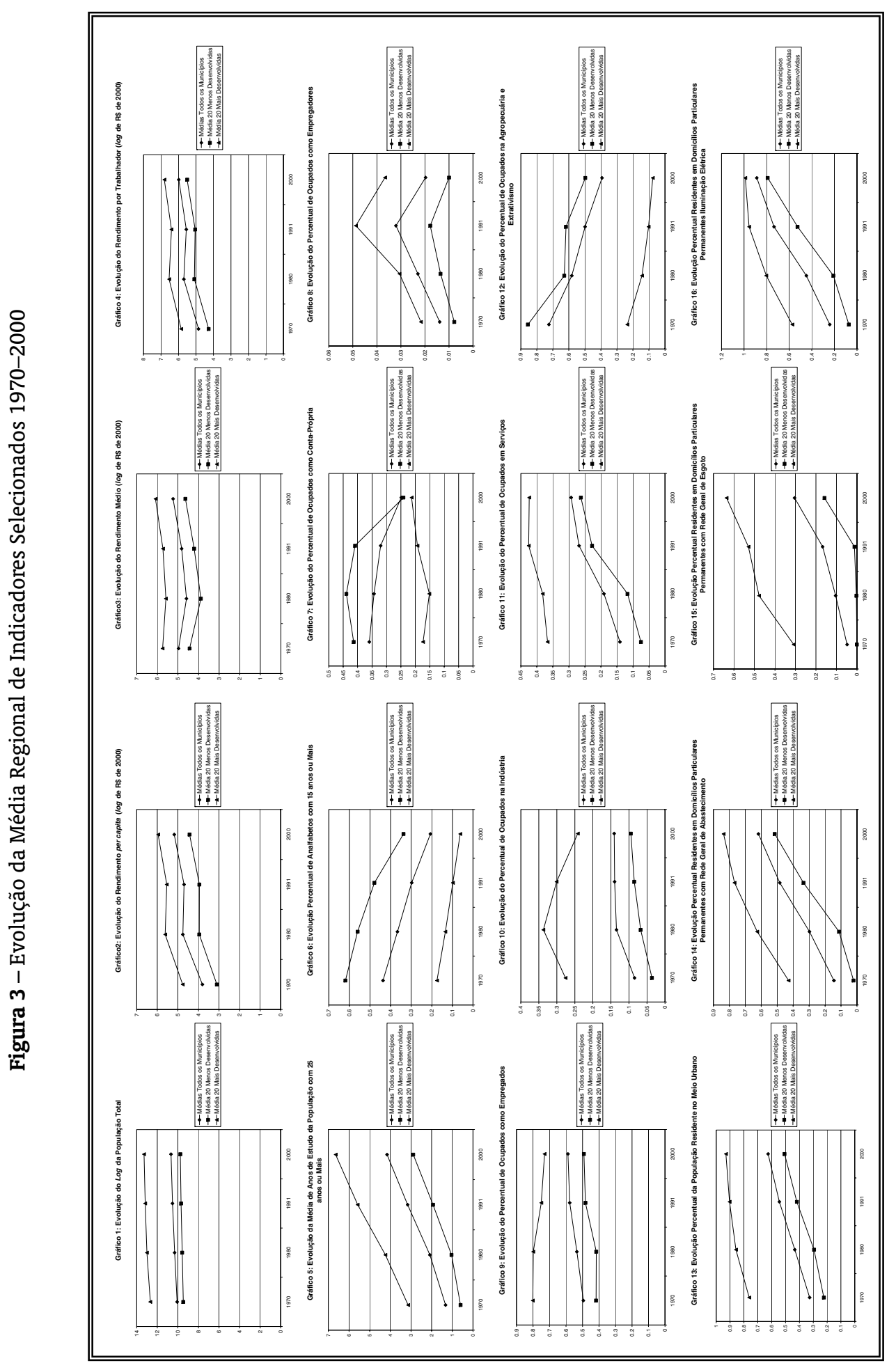

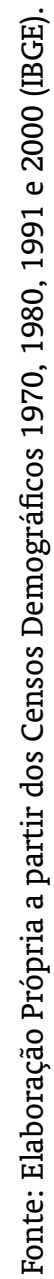


Além de gráficos da evolução desses indicadores, apresentados na Figura 3, utilizamos também regressões de tendência, estimadas por Mínimos Quadrados Ordinários, para detectar sinais de convergência ou não, conforme a seguinte equação:

$$
Y_{i t}=\alpha+\beta_{0} D_{20 i}+\beta_{1} T_{t}+\beta_{2} T_{t} \cdot D_{20 i}+\epsilon_{i t}
$$

onde $i$, de 1 até 328 , denota cada uma das unidades territoriais de análise que fazem parte das vinte regiões mais desenvolvidas e das vintes regiões menos desenvolvidas; $t$, de 1 até 4 , indica o ano censitário; $Y_{i t}$ é o valor do indicador sócio-econômico analisado, $\alpha$ é o coeficiente da constante, que dá a média do indicador nas vinte regiões mais desenvolvidas; $D_{20}$ é a dummy que indica se a unidade territorial de análise faz parte de um das vinte regiões de menor desenvolvimento, $T$ é uma tendência temporal linear, variando de 0 até 3 , segundo o ano censitário, de 1970 a 2000 . A diferença inicial na média do indicador entre as regiões mais e menos desenvolvidas é dado por $\beta_{0}$. O coeficiente de $T, \beta_{1}$, dá a tendência média de crescimento no indicador, de um ano censitário para outro, nas regiões mais desenvolvidas; enquanto que $\beta_{1}+\beta_{2}$, indica a tendência de crescimento para o indicador analisado nas regiões de menor desenvolvimento

Para os indicadores de população e renda, utilizamos o modelo semi-logarítmico:

$$
\ln Y_{i t}=\alpha+\beta_{0} D_{20 i}+\beta_{1} T_{t}+\beta_{2} T_{t} \cdot D_{20 i}+\epsilon_{i t}
$$

De 4 , temos que a diferença entre o $Y$ inicial (em $T=0$ ) para as regiões menos desenvolvidas $\left(D_{20}=1\right)$ e para as mais desenvolvidas $\left(D_{20}=0\right)$ é dada por $100 . \frac{Y_{1}-Y_{0}}{Y_{0}}$, como:

$$
\frac{E\left[Y_{1}\right]}{E\left[Y_{0}\right]}-1=\frac{\exp \left\{\alpha+\beta_{0} \cdot 1+\beta_{1} \cdot 0+\beta_{2} \cdot 0.1\right\}}{\exp \left\{\alpha+\beta_{0} \cdot 0+\beta_{1} \cdot 0+\beta_{2} \cdot 0.0\right\}}-1=\exp \left(\beta_{0}\right)-1
$$

uma estimativa para o efeito percentual da dummy de regiões menos desenvolvidas sobre a variável dependente é dado por $100\left[\exp \left(\beta_{0}\right)-1\right]$. Seguindo a correção de viés, proposta por Kennedy (1981), temos que a aproximação da diferença percentual entre o indicador nas regiões mais e menos desenvolvidas é igual a $\left\{\exp \left[\beta_{0}-0.5 * V\left(\beta_{0}\right)\right]-1\right\} * 100$, onde $V\left(\beta_{0}\right)$ é a variância estimada do estimador de Mínimos Quadrados Ordinários.

Uma aproximação para a tendência de crescimento percentual nas regiões de maior e menor desenvolvimento é dada respectivamente por $100 * \beta_{1}$ e $\left(100 * \beta_{1}+100 * \beta_{2}\right)$, uma vez que, de 4 temos:

$$
100 \frac{1}{Y} \frac{\delta Y}{\delta T}=100 \frac{\delta \ln Y}{\delta T}=100 \beta_{1}
$$

O gráfico 1 da Figura 3, mostra a evolução da população total, considerando a média para as unidades territoriais pertencentes às vinte regiões mais desenvolvidas, para aquelas que compõem as vintes regiões menos desenvolvidas e para todas as unidades territoriais do Brasil. O indício de que a população das regiões mais desenvolvidas tende a crescer mais do que naquelas menos desenvolvidas é confirmado pela regressão de tendência (Tabela 5). As regiões de maior desenvolvimento crescem em média, de um período censitário para outro, 26\%, ao passo que as regiões menos desenvolvidas crescem apenas $7 \%$, o que reforça a diferença média de cerca de $86 \%$ em favor das vinte regiões de maior desenvolvimento.

A análise da dimensão rendimento indica que o grupo de regiões menos desenvolvidas apresenta rendimentos per capita bastante inferiores àquele das regiões de maior desenvolvimento, e ao do Brasil como um todo. Em 2000, a média do total de rendimentos per capita era de R\$387,09, para o último grupo, valor bem acima da média de R\$ 257 para o Brasil, e mais de quatro vezes o valor de R\$ 84,03, encontrado nas vinte regiões menos desenvolvidas.

A evolução do total de rendimentos per capita (em $\log$ ), representando no Gráfico 2 (Figura 3), evidencia que os dois grupos de regiões analisados seguem trajetórias paralelas. Por outro lado, os resultados da regressão de tendência da Tabela 5, apresentam sinais muito fracos de convergência, com coeficiente 


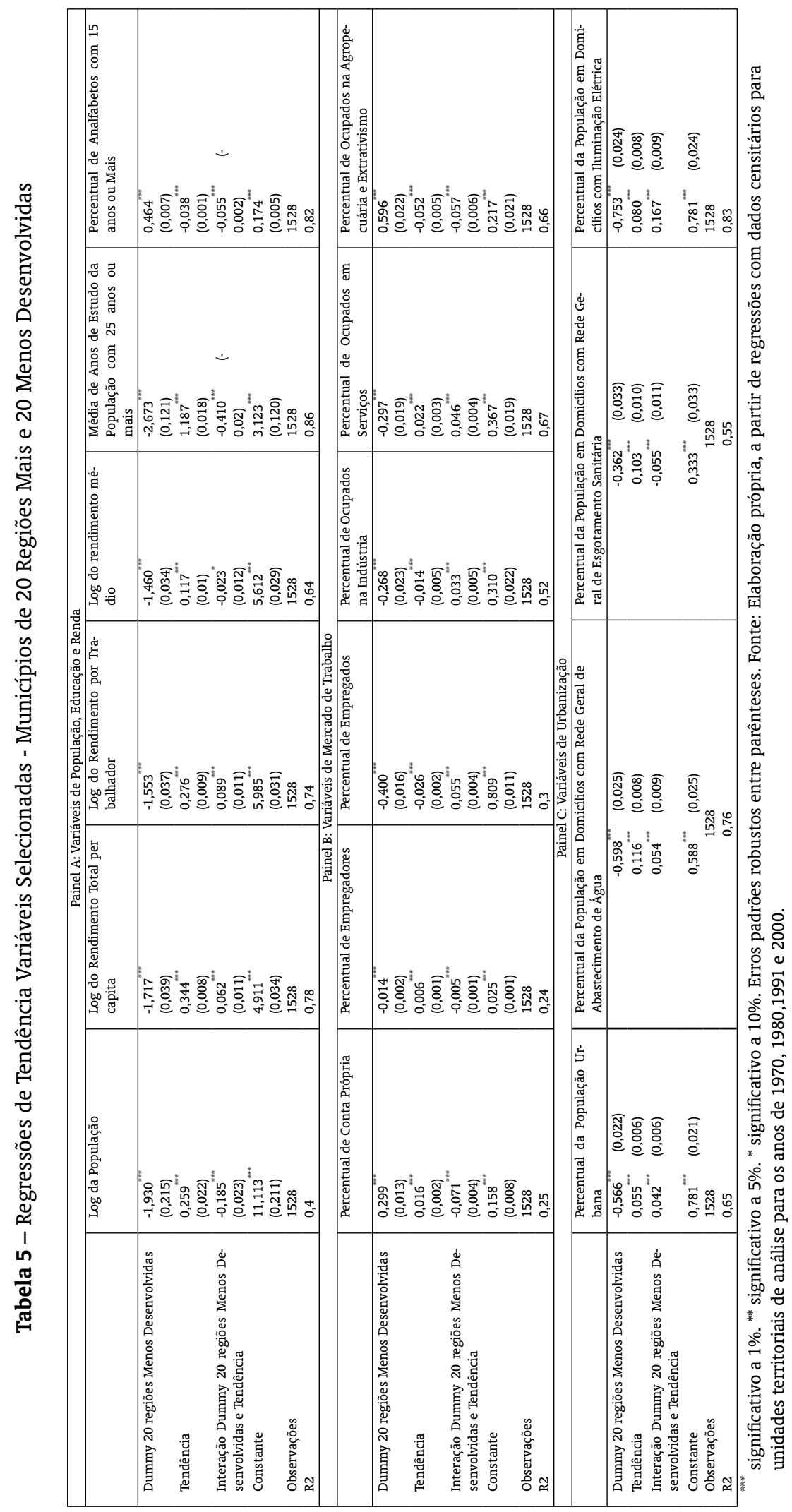

RBE Rio de Janeiro v. 61 n. 3/p. 301-330 Jul-Set 2007 
significativo para a interação da dummy de região menos desenvolvida e da tendência, mas com valor muito baixo (0.062), diante do atraso inicial, representado pelo coeficiente igual a -1,717 da dummy de região menos desenvolvida, o que significa que, em média, no estado inicial, o rendimento per capita nas regiões de menor desenvolvimento é cerca de $82 \%$ menor do que nas vinte regiões mais desenvolvidas. A partir da regressão de tendência linear, podemos afirmar, ainda, que, nas regiões mais desenvolvidas, a tendência de crescimento no rendimento per capita é de um aumento médio de $34,4 \%$ de rendimento de um período censitário para outro, enquanto que, nas regiões de menor desenvolvimento, o crescimento médio é de cerca de $41 \%$ de um Censo Demográfico para outro.

Ainda acerca dos dados de rendimento, é válido destacar que, entre as vinte regiões mais desenvolvidas, a cidade de Niterói possui o maior rendimento per capita, em 2000, cerca de R\$ 804,00. Já o maior rendimento per capita entre os municípios das regiões de hierarquia inferior é o de Caravelas, na região Centro-sul da Bahia (RS 197,52). Por outro lado, o menor rendimento per capita, entre os municípios das regiões menos desenvolvidas, não alcança R\$ 39,00 (no município de João Dias, na região do Oeste Potiguar e Sertão Paraibano), ao passo que, entre as mais desenvolvidas, chega a R\$ 180,00 (no município de Cacequi na região de Campanha, Santa Maria e Santiago, no Rio Grande do Sul).

Se na variável rendimento per capita não conseguimos verificar sinais evidentes de convergência, para a média de anos de estudo da população com 25 anos ou mais, há indícios de aumento da divergência entre os dois grupos de regiões, tanto pelo o Gráfico 5 da Figura 3, como pelos resultados da regressão de tendência da Tabela 5 . Os coeficientes da interação entre a dummy de região menos desenvolvida e a tendência são negativos, denotando que da média de anos de estudo da população com 25 anos ou mais nas regiões de menor desenvolvimento é mais lento, comparativamente àquele observado nas vinte regiões mais desenvolvidas. Enquanto que o crescimento médio na média de anos de estudo da população com 25 anos ou mais, nas regiões mais desenvolvidas, é de 1,19 anos de estudo, naquelas de menor desenvolvimento é de apenas 0,8 anos de estudo.

De um modo geral, os dados apresentados na Figura 3, confirmam uma clara dicotomia entre as vinte regiões mais desenvolvidas e as vinte regiões menos desenvolvidas, não havendo sinais evidentes de convergência. As trajetórias de evolução dos indicadores de população total, rendimento, educação, características de mercado do trabalho e infra-estrutura domiciliar, nos últimos 30 anos, são descritas, para a maioria das variáveis, por linhas que se mantêm quase paralelas até o último período censitário, indicando a existência de padrões de desenvolvimento distintos não convergentes. $O$ fato das trajetórias para os grupos de regiões mais e menos desenvolvidas se manterem paralelas é um indício de que a tendência de crescimento é semelhante para os dois grupos, contudo, como o atraso inicial nas unidades territoriais do grupo de menor desenvolvimento é acentuado, as distâncias entre os dois grupos acabam persistindo ao longo dos trinta anos considerados.

O sinal de convergência mais claro aparece apenas em indicadores do mercado de trabalho, em que a ordenação em termos de estágio de desenvolvimento é difícil. É o caso, por exemplo, do percentual de ocupados como conta-própria (Gráfico 7 da Figura 3), em que observa-se uma queda nesse percentual em regiões menos desenvolvidas e um aumento do mesmo em regiões mais desenvolvidas, de modo que os dois grupos de regiões parecem convergir para um mesmo nível. Isto porque a posição na ocupação definida como conta-própria engloba categorias bastante distintas de profissionais, ao mesmo tempo em que há um grande número de profissionais liberais, muitas vezes, bem remunerados, incluídos nessa posição, há também uma parcela significativa de pequenos agricultores ou prestadores de serviços do setor informal, força de trabalho típica dos locais de menor desenvolvimento. Logo, nas regiões mais desenvolvidas, o aumento no percentual de conta-própria pode ser tanto um reflexo do crescimento do setor de serviços modernos como do aumento do desemprego, aumentando o grau de informalidade da economia, enquanto que, naquelas de menor desenvolvimento, talvez, represente, dificuldades enfrentadas por pequenos agricultores, que podem estar sendo expulsos do mercado de trabalho formal. De 1991 para 2000, houve um aumento do percentual médio dos trabalhadores sem remuneração, em regiões de menor desenvolvimento, de $9 \%$ para $26 \%$.

Os resultados da análise gráfica para os diversos indicadores, a exemplo do que foi constatado para 
o rendimento per capita, para a média de anos de estudo da população com 25 anos ou mais e para a população total, são confirmados pelas regressões de tendência apresentadas na Tabela 5. A análise das regressões de tendência reforça, por exemplo, os sinais de convergência (Gráfico 16 da Figura 3) para o percentual de população residente em domicílios com iluminação elétrica, a tendência de crescimento das regiões menos desenvolvidas é de 0,247 contra 0,080 das regiões mais desenvolvidas.

Embora apareçam alguns sinais de convergência quando se analisam os coeficientes da interação entre a dummy de região de menor desenvolvimento e a tendência, significativos e positivos para indicadores como rendimento por trabalhador, rendimento per capita, percentual de ocupados na indústria, percentual da população urbana e percentual da população em domicílios com rede geral de abastecimento, as diferenças no crescimento favoráveis às regiões de menor desenvolvimento não parecem suficientes para reduzir o atraso inicial.

Por fim, cabe destacar que, quando refazemos o exercício alterando o corte de vinte regiões mais e menos desenvolvidas para sessenta e, em seguida, para cem regiões no topo e extremidade da nossa hierarquia de desenvolvimento, os resultados se mantém praticamente inalterados, indicando uma robustez dos mesmos (Tabelas 6 e 7; Figuras 4 e 5; em Anexo).

Em síntese, com a análise dos dados apresentados, é possível afirmar que existe uma forte desigualdade de desenvolvimento no Brasil, que não coincide com as divisões administrativas do território.

\section{CONCLUSÃO}

Este artigo avalia a convergência entre regiões brasileiras através de uma detalhada análise descritiva que identifica as regiões de maior e menor desenvolvimento a partir do estado inicial em 1970. Os resultados mostram que: i) a identificação de regiões homogêneas, em termos de vetores de atributos associados a padrões de desenvolvimento, não coincide com a divisão administrativa do território e ii) não há sinais de convergência ao longo do período analisado.

Nesse sentido, é fundamental salientar a concentração de regiões de menor desenvolvimento Nordeste do país, confirmando o atraso histórico dessa macrorregião. Contudo, a regionalização e identificação de regiões mais e menos desenvolvidas, aqui propostas, mostraram também que o Nordeste, já na década de 70, não era um espaço homogêneo. Embora, dentre as vinte regiões de menor desenvolvimento, todas estivessem localizadas naquela macrorregião e em áreas vizinhas à mesma, Salvador, capital da Bahia, o maior Estado nordestino em extensão territorial, era a décima sexta região de maior desenvolvimento. Da mesma forma, os espaços das macrorregiões mais desenvolvidas também não são homogêneos, surgindo manchas de menor desenvolvimento que fragmentam o território das áreas prósperas como, por exemplo, no Estado de Minas Gerais.

\section{Referências Bibliográficas}

Araújo, T. (1995). Planejamento regional e relações intergovernamentais. In Affonso, R. d. B. Á. \& Silva, P. L. B., editors, A federação em perspectiva: ensaios selecionados. FUNDAP, São Paulo.

Assunção, R., Lage, J., \& Reis, E. (2002). Análise de conglomerados espaciais via árvore geradora mínima. Revista Brasileira de Estatística, 63(220):7-24.

Azzoni, C., Menezes, T., Menezes, N., \& Neto, R. (2000). Geografia e convergência da renda entre os estados brasileiros. In Henriques, R., editor, Desigualdade e pobreza no Brasil, pages 299-343. IPEA, Rio de Janeiro.

Azzoni, C. R. (2001). Economic growth and regional income inequality in brazil. The Annals of Regional Science, 35(1):133-152. available at http://ideas.repec.org/a/spr/anresc/v35y2001i1p133-152.html. 
Bairoch, P. (1988). Cities and Economic Development: from the down of History to the Present. University of Chicago Press, Chicago,IL.

Banerjee, A. \& Duflo, E. (2004). Growth theory through the lens of development economics. MIT.

Barro, R. J. (1991). Economic growth in a cross section of countries. The Quarterly Journal of Economics, 106(2):407-43. available at http://ideas.repec.org/a/tpr/qjecon/v106y1991i2p407-43. html.

Barro, R. J. \& Sala-i Martin, X. (1992). Convergence. Journal of Political Economy, 100(2):223-51. available at http://ideas.repec.org/a/ucp/jpolec/v100y1992i2p223-51.html.

Basu, K. (1999). Child labor: Cause, consequence, and cure, with remarks on international labor standards. Journal of Economic Literature, 37(3):1083-1119. available at http://ideas .repec .org/a/ aea/jeclit/v37y1999i3p1083-1119.html.

Basu, K. \& Van, P. H. (1998). The economics of child labor. American Economic Review, 88:412-427.

Baumol, W. J. (1986). Productivity growth, convergence, and welfare: What the long-run data show. American Economic Review, 76(5):1072-85. available at http://ideas.repec.org/a/aea/aecrev/ v76y1986i5p1072-85.html.

Becker, G. S. (1991). A treatise on the family. Harvard University Press, Cambridge.

Cano, W. (1994). Perspectivas para a questão regional no brasil. Ensaios FEE, 15(2):312-320.

Cassen, R. H. (1978). Current trends in population change and their causes. Population and Development Review, 4(2):331-53.

Diniz, C. C. \& Lemos, M. B. (1989). Dinâmica regional e suas perspectivas no brasil. In Para a década de 90: prioridades e perspectivas de políticas públicas. Instituto de Planejamento Econômico e Social IPEA/IPLAN, Brasília.

Durlauf, S. N. \& Johnson, P. A. (1995). Multiple regimes and cross-country growth behaviour. Journal of Applied Econometrics, 10(4):365-84. available at http://ideas.repec.org/a/jae/japmet/ v10y1995i4p365-84.html.

Ferreira, A. H. \& Diniz, C. C. (1995). Convergência entre rendas per capita estaduais no brasil. Revista de Economia Política, 15(4):38-56.

Ferreira, P. C. \& Ellery Jr., R. (1996). Convergência entre renda per capita dos estados brasileiros. Revista de Econometria, 16.

Fishlow, A. (1972). Brazilian size distribution of income. American Economic Review, 62(2):391-402. available at http://ideas.repec.org/a/aea/aecrev/v62y1972i2p391-402.html.

Fleming, J. (1955). External economies and the doctrine of balanced growth. Economic Journal, 65:241256.

Galvão, A. C. (1996). Alguns comentários sobre a experiência brasileira de política regional e suas perspectivas. In A política regional na era da globalização. IPEA/Konrad Adenauer Stiftung.

Grier, K. B. \& Tullock, G. (1989). An empirical analysis of cross-national economic growth, 1951-1980. Journal of Monetary Economics, 24(2):259-276. available at http://ideas.repec.org/a/eee/moneco/v24y1989i2p259-276.html. 
Guimarães Neto, L. (1995). Desigualdades regionais e federalismo. In Affonso, Rui de Brito Álvares e Silva, P. L. B., editor, Desigualdades regionais e desenvolvimento. FUNDAP: Editora da Universidade Estadual Paulista, São Paulo.

Haddad, P. (1996). A experiência brasileira de planejamento regional e suas perspectivas. In A política regional na era da globalização. IPEA/ Konrad Adenauer Stiftung.

Haddad, P. R. (1993). Regiões, regionalismos e desequilíbrios espaciais de desenvolvimento: algumas reflexões. Indicadores Econômicos FEE, 21(2).

Harris, J. R. \& Todaro, M. P. (1970). Migration, unemployment \& development: A two-sector analysis. American Economic Review, 60(1):126-42. available at http://ideas . repec .org/a/aea/aecrev/ v60y1970i1p126-42.html.

Heer, D. M. \& Smith, D. O. (1968). Mortality level, desired family size, and population increase. Demography, 5(1):104-21.

Hirschman, A. (1958). The strategy of economic development. Yale University Press, New Haven.

Holtz-Eakin, D. (1993). Solow and the states: Capital accumulation, productivity,and economic growth. National Tax Journal, 46:425-439.

Isard, W. \& Bramhall, D. F. (1960). Methods of Regional Analysis: An Introduction to Regional Science. MIT, Massachusetts.

Johnson, R. A. \& Wichern, D. (2002). Applied multivariate analysis. Prentice Hall, 5 edition.

Kennedy, P. E. (1981). Estimation with correctly interpreted dummy variables in semilogarithmic equations. American Economic Review, 71(4):801. available at http://ideas.repec.org/a/aea/ aecrev/v71y1981i4p801.html.

Kirk, D. (1996). Demographic transition theory. Population Studies, 50(3):361-87.

Kormendi, R. C. \& Meguire, P. G. (1985). Macroeconomic determinants of growth: Cross-country evidence. Journal of Monetary Economics, 16(2):141-163. available at http://ideas.repec.org/a/ eee/moneco/v16y1985i2p141-163.html.

Kuznets, S. (1966). Modern economic growth: rate structure and spread. Yale University Press.

Laurini, M., Andrade, E., \& Pereira, P. L. V. (2005). Income convergence clubs for brazilian municipalities: a non-parametric analysis. Applied Economics, 37(18):2099-2118. available at http://ideas.repec.org/a/taf/applec/v37y2005i18p2099-2118.html.

Lee, K., Pesaran, M. H., \& Smith, R. (1997). Growth and convergence:a multicountry empirical analysis of the solow growth model. Journal of Applied Econometrics, 12:357-392.

Lucas, R. J. (1988). On the mechanics of economic development. Journal of Monetary Economics, 22(1):342. available at http://ideas.repec.org/a/eee/moneco/v22y1988i1p3-42.html.

Magalhães, A. R. (1983). Industrialização e desenvolvimento regional: a nova indústria do Nordeste. IPEA/IPLAN, Brasília.

Mankiw, N. G., Romer, D., \& Weil, D. N. (1992). A contribution to the empirics of economic growth. The Quarterly Journal of Economics, 107(2):407-37. available at http : //ideas . repec .org/a/tpr/ qjecon/v107y1992i2p407-37.html. 
Maravalle, M. \& Simeone, B. (1995). A spanning tree heuristic for regional clustering. Comm. Statist. Theory Methods, 24:625-639.

Maravalle, M. \& Simeone, B. (1997). Clustering on trees. Computational Statistics \& Data Analysis, 24:217234.

Mason, K. O. (1997). Explaining fertility transitions. Demography, 34(4):443-54.

Mossi, M. B., Aroca, P., Fernandez, I. J., \& Azzoni, C. R. (2003). Growth dynamics and space in brazil. International Regional Science Review, 26:393-418.

Myrdal, G. (1957). Economy theory and under-development regions, chapter 3/4. Londres.

Nurske, R. (1953). Problems of capital formation in underdeveloped countries. Oxford University Press, Nova Iorque, 1 edition.

Oliveira, F. (1990). A metamorfose da arribaçã - fundo público e regulação na expansão econômica do nordeste. Novos Estudos CEBRAP, 27:67-92.

Ray, D. (1998). Development Economics. Princeton University Press, Nova Jersey.

Ray, D. (2000). What's new in development economics? The American Economist, 44:3-16.

Rosenstein-Rodan, P. (1943). Problems of industrialization of eastern and southeastern europe. In Meier, G., editor, Leading issues in economic development; studies in international poverty. Oxford University Press.

Sala-i Martin, X. (1996). Regional cohesion: Evidence and theories of regional growth and convergence. European Economic Review, 40:1325-1352.

Sen, A. (1984). Resources, Values and Development. Harvard University Press, Cambridge.

Solow, R. M. (1956). A contribution to the theory of economic growth. The Quarterly Journal of Economics, 70(1):65-94.

\section{A. TABELAS E FIGURAS}




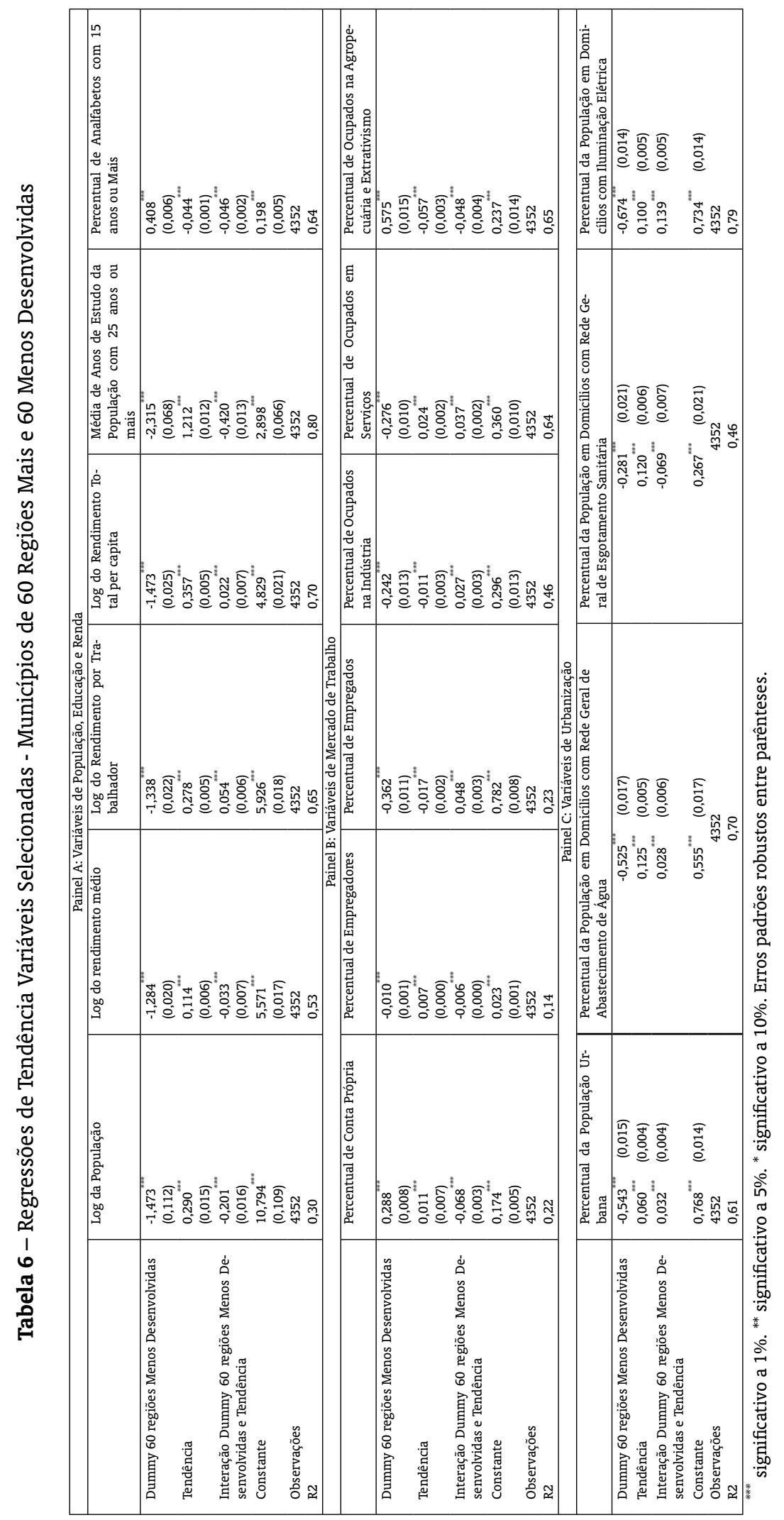

RBE Rio de Janeiro v. 61 n. 3/p. 301-330 Jul-Set 2007 


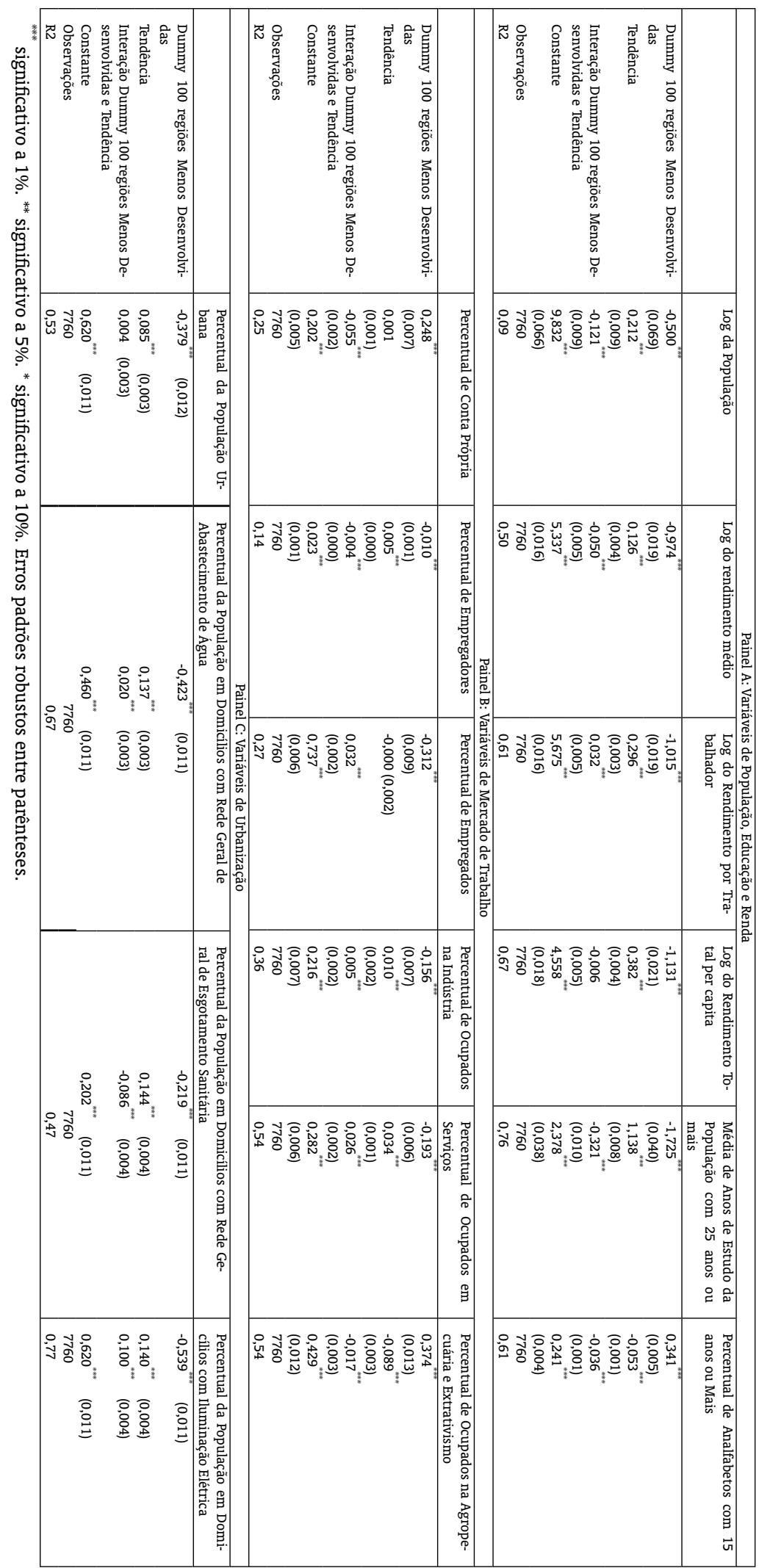

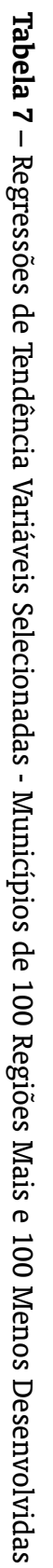




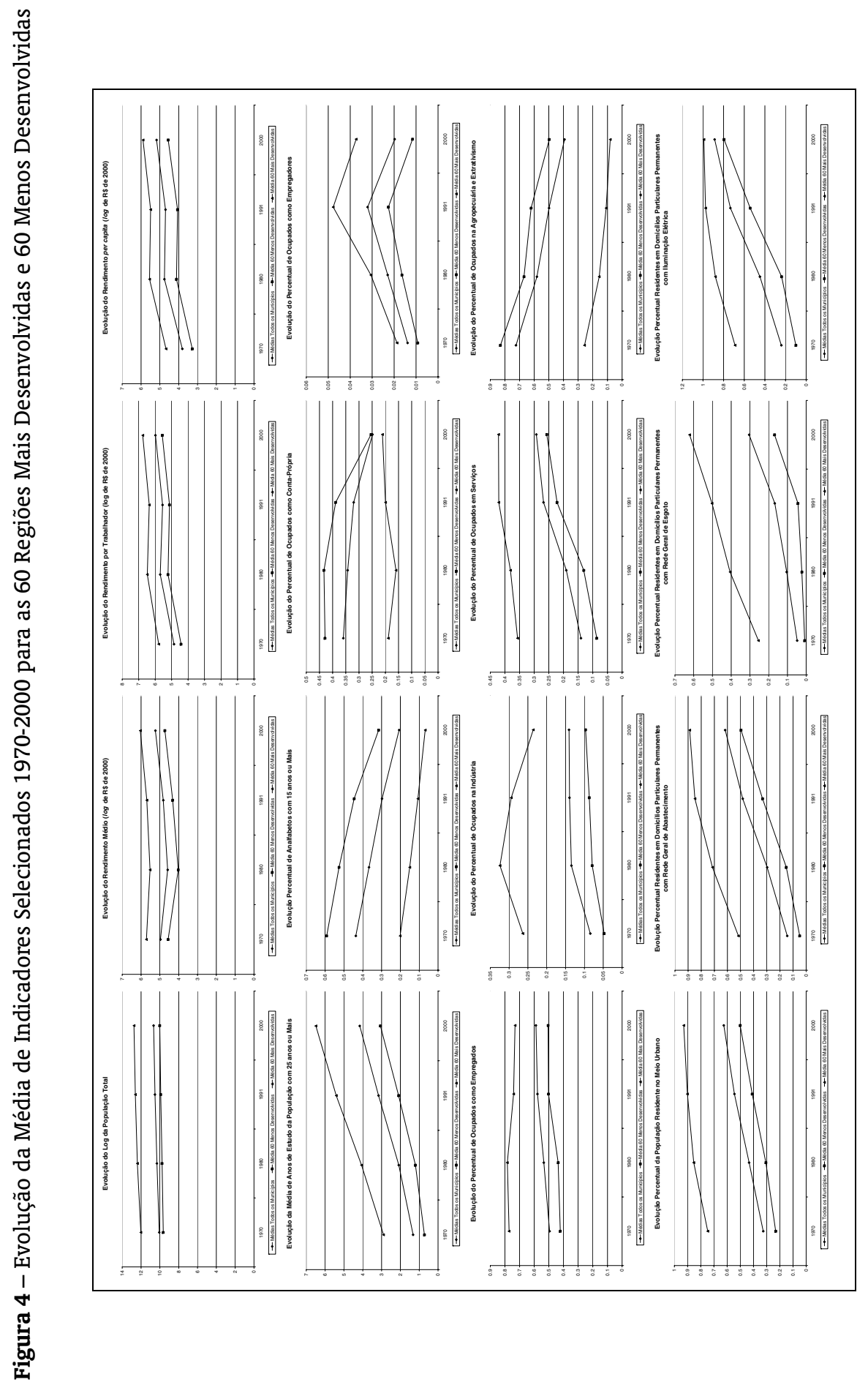

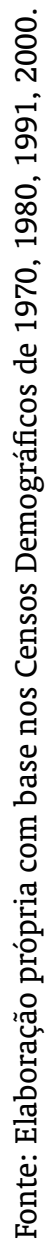




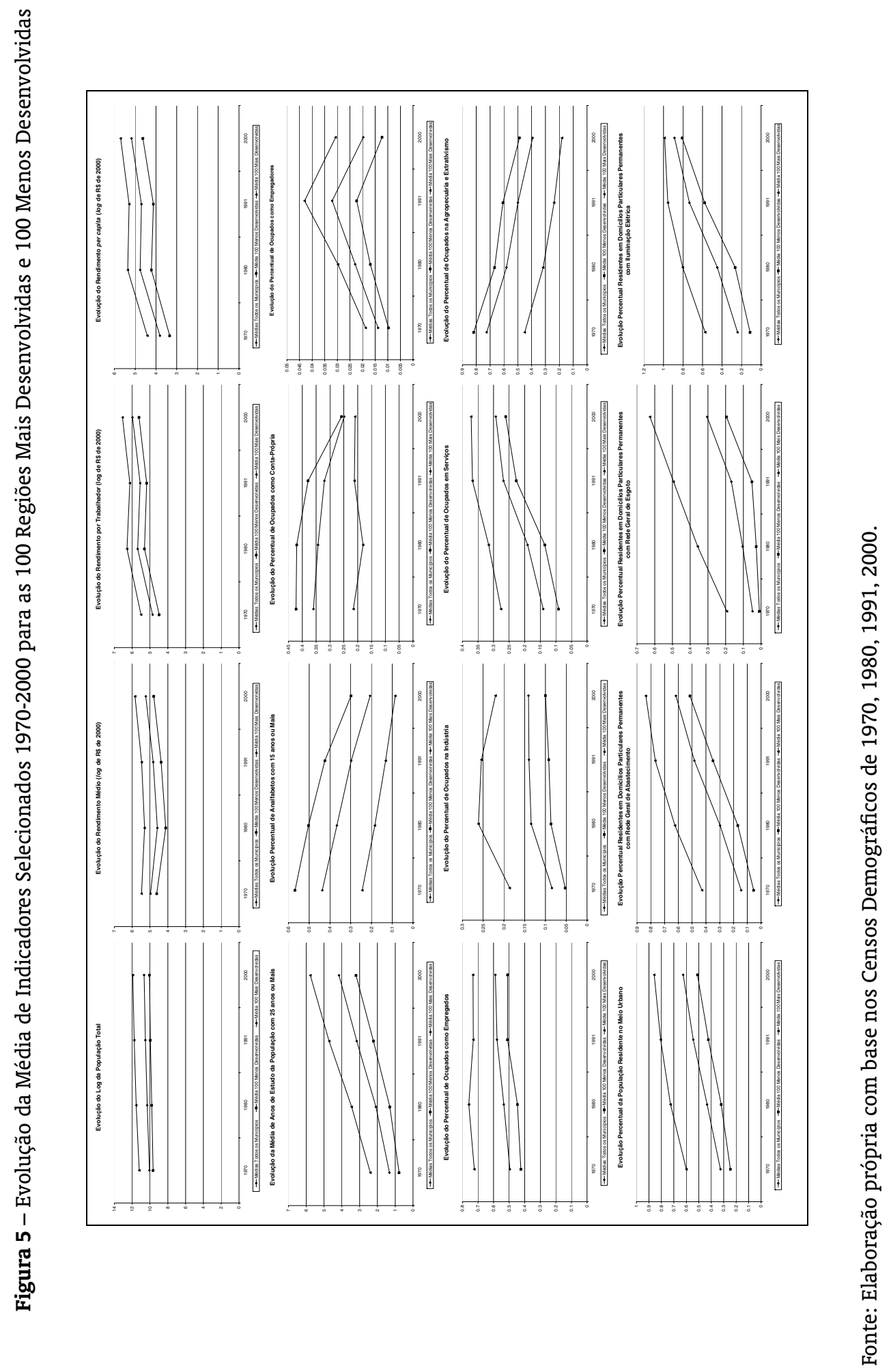

